
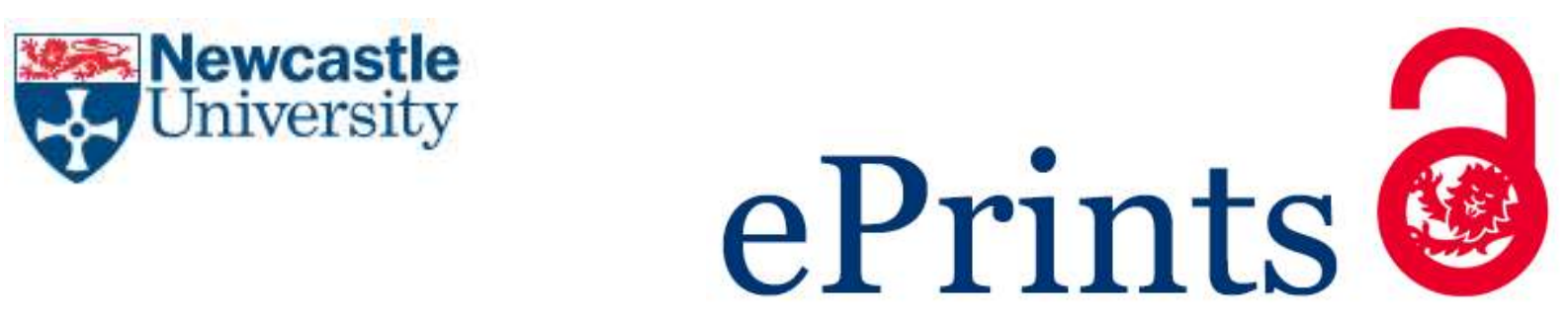

Kling G, Harvey C, Maclean M. Establishing causal order in longitudinal studies combining binary and continuous dependent variables. Organizational Research Methods 2016, 19

\title{
Copyright:
}

(C)2015 by Sage Publications

The publisher allows 'posting of the accepted version (version 2) of the article on your own personal website, your department's website or the repository of your institution without any restrictions'.

DOI link to article:

http://dx.doi.org/10.1177/1094428115618760

Date deposited:

$02 / 12 / 2015$

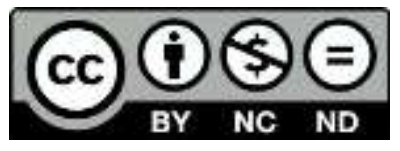

This work is licensed under a

Creative Commons Attribution-NonCommercial-NoDerivatives 4.0 International licence 


\section{Establishing Causal Order in Longitudinal Studies Combining Binary and Continuous}

\section{Dependent Variables}

Gerhard Kling, ${ }^{*}$ Charles Harvey ${ }^{\dagger}$ and Mairi Maclean ${ }^{\ddagger}$

Longitudinal studies with a mix of binary outcomes and continuous variables are common in organizational research. Selecting the dependent variable is often difficult due to conflicting theories and contradictory empirical studies. In addition, organizational researchers are confronted with methodological challenges posed by latent variables relating to observed binary outcomes and within-subject correlation. We draw on Dueker's (2005) qualitative vector autoregression (QVAR) and Lunn et al.’s (2014) multivariate probit model to develop a solution to these problems in the form of a qualitative short panel vector autoregression (QSP-VAR). The QSP-VAR combines binary and continuous variables into a single vector of dependent variables, making every variable endogenous a priori. The QSP-VAR identifies causal order, reveals within-subject correlation and accounts for latent variables. Using a Bayesian approach, the QSP-VAR provides reliable inference for short time dimension longitudinal research. This is demonstrated through analysis of the durability of elite corporate agents, social networks and firm performance in France. We provide our OpenBUGS code to enable implementation of the QSP-VAR by other researchers.

\section{Keywords}

Bayesian statistics, binary dependent variables, causality, longitudinal research, vector autoregression

\footnotetext{
* School of Oriental and African Studies, University of London, Thornhaugh Street, Russell Square, London WC1H OXG, phone: +44 (0)20 7898 482, email: gk17@ soas.ac.uk.

${ }^{\dagger}$ Newcastle University, 2nd Floor Armstrong Building, Newcastle upon Tyne, NE1 7RU, phone: +44 (0) 191 208 5812, email: charles.harvey@ncl.ac.uk.

¥ Newcastle University, 5 Barrack Road, Newcastle upon Tyne, NE1 4SE, phone: +44 (0)191 2081674, email: mairi.maclean@ncl.ac.uk.
} 
The potential of longitudinal research to enrich organization science has been well articulated (Hassett \& Paavilainen-Mäntymäki, 2013; Ployart \& Vandenberg, 2010). Individual and organizational actors exist in a profoundly temporal order. Their decisions are shaped by past events, and their actions have consequences for the future. Explaining changes over time, however, poses non-trivial analytical problems, not least of which is identifying causal order; the proverbial chicken and egg problem encountered, for example, when examining the interrelations between CEO power and firm performance (Daily \& Johnson, 1997). In organizational research, three methods have been applied predominantly to accord time a central role in theory building: generalized linear modeling (Ballinger, 2004; Harrison \& Hulin, 1989; Henderson, Miller \& Hambrick, 2006; Liang \& Zeger, 1986; Zeger, Liang \& Albert, 1988), random coefficient modeling (Bliese, Chan, \& Ployhart, 2007; Bliese \& Ployhart, 2002; Schonfeld \& Rindskopf, 2007), and latent growth modeling (Chan, 1998; Chan \& Schmitt, 2000; Ployhart \& Hakel, 1998). This paper proposes an alternative - vector autoregression - which offers advantages in detecting causal order, adding to the arsenal of analytical methods deployed in longitudinal studies.

Longitudinal studies have not been confined to analyzing changes in continuous dependent variables such as firm performance, but have also focused on binary dependent variables, as in research on CEO duality (Boyd, 1995; Rechner \& Dalton, 1991), employee turnover (Porter, Steers, Mowday \& Boulian, 1974), and market entry (Haveman \& Nonnemaker, 2000). The problem arises that observing binary outcomes only tells us whether or not an event or decision occurred, leaving the underlying decision mechanism obscured. Ballinger (2004) alleviates this problem making use of generalized linear models, such as Generalized Estimating Equations (GEE). GEE accommodate non-normal dependent variables and within-subject correlation (i.e. the outcome, $y_{i t}$ might depend on past outcomes, $\mathrm{y}_{\text {it-1 }}$ ), which might occur when subjects are measured repeatedly over time (Liang \& Zeger, 
1986; Zeger et al., 1988). A further advantage is that GEE are excellent for assessing the impact of covariates on outcomes through marginalization, revealing average responses to changes in covariates (Ballinger, 2004: 130).

Conventional methods such as generalized linear modeling, random coefficient modeling, and latent growth models are single-equation models whose "broad scientific objective is to describe an outcome, $\mathrm{y}_{\mathrm{it}}$, for subject $\mathrm{i}$ at time $\mathrm{t}$ as a function of covariates, $\mathrm{x}_{\mathrm{it}}$ " (Zeger et al., 1988: p.1049). When a single equation is estimated, researchers need to specify the dependent variable (e.g. the response $y_{i t}$ ) up front, implying the existence of a known or readily deducible causal order. This is not true to life in many of the scenarios encountered in organizational research. Whenever a change in organizational performance is linked with a change in management practice, the problem of specifying causal order arises. Delarue, Van Hootegem, Procter, \& Burridge (2008: p.142), for instance, following an exhaustive review of team working and organizational performance, conclude that it remains “(...) unclear what comes first: do HRM practices cause good performance or does good performance lead to the implementation of certain HRM practices?” Likewise, Daily and Johnson (1997: p.97) report with respect to their analysis of firm performance and CEO power that "performance was found to be both an antecedent condition and an outcome of CEO power."

We propose a vector autoregression (VAR) approach that does not require definition of causal order a priori. In fact, a VAR reveals causal order after the data is analyzed. Within organization science, however, the VAR approach, is not yet established, as evidenced by lack of coverage to date in this journal. In organizational research, structural equation modeling (SEM) has been favored (e.g. latent growth modeling), and quite often researchers have assumed that SEMs can detect causality. But this is not the case (Bollen \& Pearl, 2013). This said, somewhat similar methods have been applied in organizational research. For instance, in their seminal paper on the job satisfaction-performance relationship, Bateman 
and Organ (1983) conduct a causal analysis applying a cross-lagged regression building on Kenny (1975) and Rogosa (1980). Their model (1983: p.590) resembles a VAR with one lag, analyzing data collected at two points in time. This constitutes a longitudinal study with short time dimension, a research design common in organizational research due to limited access to data or high costs of data collection (Pettigrew, 1990; Taris, 2013), suggesting that the VAR approach has potential for wider application. To realize this potential, it is necessary to overcome the methodological issues arising in short time dimension studies due to hidden (and untestable) time series properties (e.g. stationarity) (Binder, Hsiao, \& Pesaran, 2005; Willett, 1989). In addition, the standard VAR approach does not permit binary dependent variables, common in organizational research.

To establish causal order in longitudinal studies with binary outcomes and continuous variables, we develop a qualitative short panel vector autoregression (QSP-VAR). In line with Hsiao (2014), we use 'longitudinal data' and 'panel data' interchangeably in observing several subjects repeatedly over time. The QSP-VAR combines several binary and continuous variables into a single vector of dependent variables. Lagged dependent variables explain current values, revealing causal order and within-subject correlation. Relying on Bayesian inference, the QSP-VAR can handle longitudinal data with a curtailed time dimension (Bijak \& Wiśniowski, 2009). The QSP-VAR draws on Dueker's (2005) qualitative vector autoregression (QVAR), which combines one binary dependent variable and a set of continuous variables to form a VAR in reduced form. Reduced form means that each dependent variable is explained by lagged rather than contemporaneous dependent variables including its own past observations. To accommodate more than one binary dependent variable, we combine the QVAR with the multivariate probit model developed by Lunn, Osorio and Whittaker (2014). Extended in this way, the QSP-VAR tests for causal order in longitudinal studies with binary and continuous dependent variables. 
Recognizing the theoretical issues encountered in the context of multivariate Bernoulli distributions (Dai, Ding, \& Wahba, 2013; Lunn et al., 2014), we focus on the underlying latent variable models as suggested by Dueker (2005) and Lunn et al. (2014). We address technical difficulties due to the instability resulting from separation using weakly informative priors (Gelman, Jakulin, Pittau, \& Su, 2008). Separation occurs when a linear combination of covariates predicts binary outcomes perfectly (Zorn, 2005). Organizational researchers use binary or categorical covariates (e.g. gender, ethnicity, occupational prestige) frequently. Including a large number of binary or categorical covariates increases the chance that a linear combination of covariates explains binary outcomes perfectly, causing separation. The problem of separation can be solved in Bayesian analysis using informative prior distributions (Albert \& Anderson, 1984). The advantage of the method developed by Gelman et al. (2008) is that weakly-informative prior distributions are sufficient to address separation.

In what follows, we first locate the origins, development and advantages of vector autoregression in determining causal order, and set the stage for our illustration of the QSPVAR. Next, we elaborate and specify the QSP-VAR before implementing it using OpenBUGS. There follows a demonstration of the QSP-VAR through analysis of an extensive short panel dataset on the French corporate elite (Maclean, Harvey, \& Kling, 2014). Following discussion of the potentialities and limitations of our study, we conclude that the QSP-VAR is a valuable analytical tool for organizational researchers confronted with binary dependent variables, indeterminate causality and limited points of measurement.

\section{Research Context}

\section{Vector Autoregression and Granger Causality}

Sims's (1972, 1980a, 1980b) seminal work on vector autoregression (VAR) has stood the test of time, routinely applied as a core method in macroeconomics. Since the VAR takes 
multiple variables as dependent, researchers do not have to specify alleged causal order prior to data analysis. In contrast to conventional methods, the VAR is a multiple-equation model which adopts an autoregressive structure so that variables measured in the past can impact on variables in the present. The model identifies causal order, referred to as Granger causality, wherein the past impinges on the present, without of course the present impacting on the past (Granger, 1969). Using frequentist and Bayesian methods, panel VARs have been introduced for longitudinal data (Canova \& Ciccarelli, 2013). Panel VARs are especially appealing for research in organization science as they treat all variables as endogenous, revealing causal order. Yet, current panel VARs cannot accommodate binary dependent variables commonly found in organizational research. We seek to overcome this limitation in the present paper. Our model, the QSP-VAR, extends Dueker's (2005) QVAR to accommodate both binary and continuous dependent variables. Drawing on the multivariate probit model developed by Lunn et al. (2014), it permits several binary variables that exhibit an arbitrary correlation structure. This feature is crucial when modeling real-world situations, e.g. individuals might occupy multiple positions at the same time, as we demonstrate in what follows.

We take a Bayesian approach to estimate the QSP-VAR, as maximum likelihood estimation would entail high-dimensional numerical integration due to binary dependent variables, questioning its tractability (Zyphur \& Oswald, 2015). Bayesian methods are common in panel VARs, thus aligning our approach with existing models (Canova \& Ciccarelli, 2013), especially those of Dueker (2005) and Lunn et al. (2014), which in effect are 'parents' to the QSP-VAR.

\section{Research Setting}

To illustrate the potentialities of the QSP-VAR, we put our method to work in analyzing the determinants of top executive durability in corporate France. The theoretical domain is the 
causal relationships thought to exist between top executive tenure, firm performance and social networks, focusing inter alia on critical questions concerning CEO power (Adams, Almeida \& Ferreira, 2005), CEO duality (Boyd, 1995), board composition (Ocasio, 1994; Shen \& Cannella, 2002), ownership (Pérez-González, 2006), governance (Marcel, Cowen, \& Ballinger, 2013), and CEO succession (Datta \& Rajagopalan, 1998). The literature is large, growing and interrelated, reflecting an enduring fascination with the pivotal role played by powerful CEOs in the corporate world. Three interrelated themes are central to our research. The first is the two-way relationship that exists between executive tenure and firm performance. On the one hand, there is evidence to suggest that firm performance may decline as executive tenure increases, and that this decline is swiftest in the most dynamic industries (Henderson et al., 2006). On the other hand, there is a considerable body of evidence to suggest that weak firm performance is the foremost cause of CEO removal (Allgood \& Farrell, 2000; Brickley, 2003; Dalton \& Kesner, 1985), length of tenure being shorter in highly competitive industries (DeFond \& Park, 1999). What is most striking is the general lack of agreement on direction of causality between tenure and firm performance (Cao, Maruping, \& Takeuchi, 2006; Daily \& Johnson, 1997; Zajac, 1990).

The second theme concerns length of tenure in top executive roles and the mechanisms that help or hinder survival. Hambrick and Fukotomi (1991) have likened CEO tenure to the passing of seasons, from youthful beginnings to a winter of discontent, when the advantages of continued tenure are outweighed by negative effects. The idea underlying the life-cycle approach is that CEO commitment to a particular business model yields increasingly good results when in sync with the market, but that the process reverses when inparadigm learning effects are overwhelmed by eventual lack of fit between model and market. The emerging proposition that CEO vulnerability to termination rises with time and that the best form of mitigation is continued strong firm performance is supported by Brookman and 
Thistle's (2009) analysis of survivorship amongst 2,325 CEOs employed by 1,472 US companies between 1993 and 2001. However, risk of termination has been shown elsewhere not to rise evenly over time, high vulnerability during the early years subsiding when CEOs become entrenched before increasing again at the end of the life-cycle (Gregory-Smith, Thompson \& Wright, 2009). Entrenchment is marked by a greater toleration of poor results by boards of directors, and is especially acute when power is concentrated in the hands of a CEO-Chairman (Goyal \& Park, 2002) or a CEO anointed by an owning family (PérezGonzález, 2006). It matters less in fast-changing industries like computing in which termination rates are higher than in more stable industries like food processing (Henderson et al., 2006), and may be circumvented when things go badly by insubordination on the part of insider board members (Ocasio, 1994; Shen \& Cannella, 2002).

The third theme concerns the relationship between survivorship and social networks (Geletkanycz \& Hambrick, 1997; Gulati, 1995; Kijkuit \& van den Ende, 2010; Paquin \& Howard-Grenville, 2013). This recognizes that the power and resources impinging on both top executive durability and firm performance are distributed across networks, and not simply concentrated within firms (Ahuja, 2000; Mehra, Dixon, Brass, \& Robertson, 2006; Useem \& Karabel, 1986; Zaheer, Gözübüyük, \& Milanova, 2010). The literature has focused mainly on the positive side of interfirm networks (Burt, 1980; Burt, Hogarth, \& Michaud, 2000; Shropshire, 2010). Individuals create ties (interlocks) between companies when they serve on multiple boards, enabling two-way flows of commercially sensitive information (Mizruchi \& Stearns, 1988). Zajac and Westphal (1996: p.254) report that “(...) discussions have tended to emphasize the role of such ties in spreading knowledge and awareness about specific organizational changes." This positive connotation suggests that interlocks, in constituting interfirm networks, should enhance an organization's capabilities and performance (Mehra et al., 2006). Geletkanycz and Boyd (2011) are more sanguine, acknowledging the possible 
downside that CEOs whose time is scarce might become distracted if outside interests become too demanding, eroding the informational, learning and affiliation benefits of network embeddedness. Nonetheless they find that for firms facing competitive constraints on growth, CEO outside directorships are positively related to long-term performance. Recognizing the pertinence of Mizruchi's (1996: p.277) observation that "interlocks occur between organizations, but they are created by individuals", this raises a further interesting question: if the network ties of CEOs are of financial value to their primary employer, what might they, as individual agents, stand to gain personally by serving as ties within corporate networks (Gulati \& Srivastava, 2014)? One possible answer, tested for by Geletkanycz, Boyd and Finkelstein (2001) using a sample of 460 US corporations listed in the 1987 Fortune 1000 , is that they are better remunerated. Their study provides qualified support for their hypothesis, which is found to hold true for more highly diversified firms but not others. A further possibility is that networks enhance durability by providing a cushion against dips in performance, enabling executives to remain active for longer in the upper echelons of the corporate world (Maclean et al., 2014).

Research on top executive durability, social networks and firm performance is ideal for illustrating the qualities and potential of the QSP-VAR. A longitudinal research design is necessary to capture changes in position over relatively short periods, and both binary and continuous dependent variables demand consideration. Modeling survivorship necessarily posits binary dependent variables exhibiting within-subject correlation because an agent's current role depends on previous roles (Liebowitz \& Margolis, 1995). Continuous dependent variables such as firm performance, which exhibit autocorrelation, also need to be incorporated (Friedman \& Singh, 1989; Lubatkin, Chung, Rogers, \& Owers, 1989). To explain durability in 'command posts' (Mills, 1956: p.4), we need to explain how agents gain appointment to initial positions and how occupancy influences the probability of continuation 
(Maclean, Harvey, \& Chia, 2010; Useem \& Karabel, 1986). Initial positions refer to the start of the investigation period, which we call the 'initial phase'. The QSP-VAR does not require an 'initial phase'. As in a standard VAR, the initial observations can be regarded as observed starting values, unexplained by covariates. In the context of organization science, we would like to understand how individuals managed to obtain their initial positions.

Figure 1 illustrates the structure of our model. First, the initial phase explains how agents occupied their initial positions. To capture the formation of networks, four types of positions are considered labelled $\mathrm{y}_{1}, \mathrm{y}_{2}, \mathrm{y}_{3}$ and $\mathrm{y}_{4}$. Lacking full data on employment history, we use a set of exogenous variables, including nationality and gender, to explain initial positions. These exogenous variables are 'variables of fate' not decided in our model (Maclean et al., 2014). Second, subsequent positions form the QSP-VAR together with measures of the size and reach of networks, and performance measures. The QSP-VAR permits an autoregressive structure so that past realizations of dependent variables affect current values. Accordingly, after the initial phase, wherein the ascent of agents to their first command position is explained by a set of exogenous variables, the vector of dependent variables contains positions, networks, and firm performance, making all variables endogenous a priori. This is the main benefit of the QSP-VAR since every variable is endogenous, explained by past realizations of all variables.

[Insert Figure 1 here]

\section{Developing the QSP-VAR}

We generalize Dueker's (2005) QVAR by considering more than one binary variable, labelled $\mathrm{y}_{\mathrm{it}}^{\mathrm{p}}$, with $\mathrm{p}=1,2, \ldots, \mathrm{P}$ of cross-sectional units labelled $\mathrm{i}(\mathrm{i}=1,2, \ldots, \mathrm{N})$ at time $\mathrm{t}$ $(\mathrm{t}=1,2, \ldots, \mathrm{T})$. For instance, if the observed binary variable $\mathrm{y}_{21}{ }^{3}$ takes the value one, it indicates that individual $\mathrm{i}=2$ at point in time $\mathrm{t}=1$ holds position $\mathrm{p}=3$. These observed binary outcomes 
(e.g. whether an agent holds a position or not) relate to an unobserved (or latent) underlying decision process. Consistent with Dueker (2005) and Eichengreen, Watson and Grossman (1985), we adopt the latent variable model presented in equation (1), in which a star indicates latent variables.

$$
\begin{gathered}
y_{i t}^{p}=\left\{\begin{array}{l}
1 \text { if } y_{i t}^{p *}>0 \\
0 \text { if } y_{i t}^{p *} \leq 0
\end{array}\right. \\
\text { where } p=\{1,2, \ldots, P\}, i=\{1,2, \ldots, N\}, t=\{1,2, \ldots, T\}
\end{gathered}
$$

Equation (1) states that the observed binary outcome (e.g. holding a position) is equal to one if the underlying latent variable is strictly positive and zero otherwise. We only detect whether agents actually hold a position (or not); for instance, we cannot say if they came close to securing a position but narrowly failed to do so. In our model, latent variables follow a VAR with one lag in reduced form, which is a multivariate extension of the autoregressive process with one lag used by Dueker (2005) and Eichengreen et al. (1985).

$$
\left[\begin{array}{c}
y_{i t}^{1 *} \\
\vdots \\
y_{i t}^{P *}
\end{array}\right]=\mathbf{y}_{\mathbf{i t}}^{*}=\boldsymbol{\alpha}+\mathbf{\Xi} \mathbf{y}_{\mathbf{i t}-\mathbf{1}}^{*}+\boldsymbol{\epsilon}_{\mathbf{i t}}
$$

Equation (2) describes the VAR(1) in latent variables, where the vector $\boldsymbol{\alpha}$ is a $\mathrm{P} \times 1$ column vector of constant terms, whereas $\boldsymbol{\Xi}$ is a $\mathrm{P} \times \mathrm{P}$ dimensional coefficient matrix. The error term is multivariate normal with mean 0 and covariance matrix $\boldsymbol{\Omega}$, which suggests a multivariate probit approach. ${ }^{2}$ Following Lunn et al. (2014), we allow an arbitrary correlation structure; thus, we do not impose any restrictions on the covariance matrix $\boldsymbol{\Omega}$. For instance, equation (2) permits that positions at a particular point in time are correlated. So, for example, being a CEO can be related to being a non-executive director of another company. The equation captures dynamics in the sense that past positions at t-1 can affect holding positions at t. It is important to understand that the latent variable model is a convenient way to 
describe the multivariate distribution of binary variables without resorting to multivariate Bernoulli distributions (Dai et al., 2013, Lunn et al., 2014).

The next step is to combine the multivariate probit model described in equations (1) and (2) with a set of $K$ continuous variables captured in the column vector $\mathbf{x}_{\mathbf{i t}}$ with dimension $\mathrm{K} \times 1$. In our example, these continuous variables include measures of size and range of networks as well as performance indicators. Hence, we obtain the following panel vector autoregression in reduced form. Following Dueker (2005), we use augmented vectors to combine column vectors for latent variables $\mathbf{y}_{\mathbf{i t}}{ }^{*}$ and observed continuous variables $\mathbf{x}_{\mathbf{i t}}$.

$$
\begin{aligned}
& {\left[\begin{array}{l}
\mathbf{y}_{\mathrm{it}}^{*} \\
\mathbf{x}_{\mathrm{it}}
\end{array}\right]=\boldsymbol{\beta}+\boldsymbol{\Gamma}_{\mathbf{1}}\left[\begin{array}{l}
\mathbf{y}_{\mathrm{it}-\mathbf{1}}^{*} \\
\mathbf{x}_{\mathrm{it}-\mathbf{1}}
\end{array}\right]+\boldsymbol{\Gamma}_{\mathbf{2}} \mathbf{z}_{\mathrm{it}-\mathbf{1}}+\mathbf{u}_{\mathrm{it}}} \\
& (i=1, \ldots, N, t=1, \ldots, T)
\end{aligned}
$$

We include a set of exogenous variables captured in column vector $\mathbf{z}_{\mathbf{i t}-\mathbf{1}}$. All variables on the right-hand side of equation (3) are lagged by one time period (i.e. their values are observed at $\mathrm{t}-1$ ). As lagged variables are known at point in time $\mathrm{t}$, they are said to be predetermined, ensuring weak exogeneity. ${ }^{3}$ The coefficient matrices $\boldsymbol{\Gamma}_{\mathbf{1}}$ and $\boldsymbol{\Gamma}_{\mathbf{2}}$ can be restricted to resemble Figure 1 or another structure the researcher wishes to explore. For instance, as we lack knowledge of agents' positions before a certain point, we cannot use lagged positions to explain the ascent to initial posts. So at $\mathrm{t}=1$ (the starting point of our study), only exogenous variables (e.g. age, gender etc.) can explain initial positions. As these exogenous variables are time-invariant (or in case of age deterministic), we only use them once for explaining initial positions. Subsequent positions refer to the model captured in equation (3) and hence depend on the interplay between positions, networks and performance.

The panel vector autoregression specified in equation (3) extends Dueker's (2005) multivariate time series model to panel data. Time series data refers to observing one subject repeatedly over time, whereas longitudinal (panel) data extends observations to several subjects over time. In addition, the model considers several binary variables with arbitrary 
correlation structure, applying a multivariate probit model consistent with Lunn et al. (2014) specifying a multivariate normal distribution for both latent and observed continuous variables as prior distribution. In combination with the association between observed binary variables and associated latent variables captured in equation (1), latent variables are drawn from a truncated normal distribution (Lunn et al., 2014).

Following Dueker (2005), we apply a Markov-Chain Monte Carlo simulation (MCMC) to estimate the parameters of the model. Initial values for parameters can be specified or sampled from prior distributions. The Gibbs sampler can accommodate parameters that should be determined simultaneously but in practice are estimated in a sequential process (Gelman, Carlin, Stern, \& Rubin, 1995). All parameters have uninformative priors and therefore the Bayesian MCMC approach converges to maximum likelihood. Of course, researchers can specify informative priors (e.g. based on expert opinions), which enhances inference, especially in small samples.

We need to modify default uninformative prior distributions for parameters of the multivariate probit model as they cause computational problems due to separation. ${ }^{4}$ Separation means that a linear combination of covariates explains the binary outcome perfectly (Zorn, 2005). For instance, if all women with foreign nationality hold CEO positions, the binary outcome (i.e. being a CEO) is perfectly explained. Gelman et al. (2008) suggest weakly informative prior distributions that work in the presence of separation. Following their procedure, all continuous variables employed are standardized with mean zero and standard deviation 0.5. The weakly informative prior is the Cauchy distribution, which coincides with the Student-t distribution with one degree of freedom. Originally, Gelman et al. (2008) designed this weakly informative prior for logistic regressions, but it also works effectively for the QSP-VAR. 


\section{Implementing the QSP-VAR}

Appendix B provides our code with annotations explaining each step. OpenBUGS is available from www.openbugs.net and can be accessed through R. Bayesian methods have been used for VARs, and Bijak and Wiśniowski (2009) have released an OpenBUGS code for continuous dependent variables. Bijak and Wiśniowski (2009: 98) define the prior distribution for the three continuous dependent variables as multivariate normal with mean vector, $\mathrm{mu}[t, 1: 3]$, and precision matrix, $\mathrm{T}[1: 3,1: 3]$. Three equations explain the mean vector, which include lagged dependent variables and constant terms resulting in a VAR with one lag in reduced form. Bijak and Wiśniowski's (2009) code can be used for continuous variables in the QSP-VAR, but modifications are needed for binary variables and for the use of longitudinal data rather than time series data.

As our time dimension is short, it is easier to define each point in time separately using a lagged vector of dependent variables (labeled with the prefix i) rather than introducing a time dimension explicitly. There are different data formats used for panel data in OpenBUGS. One method of storing panel data with two points in time is to use a twodimensional array $y[i, t]$ for $i=1,2, \ldots, N$ and $t=1,2$. Our preferred approach is to split a two-dimensional array $y[i, t]$ into two one-dimensional arrays, named $y[i]$ for $t=2$ and $i_{\text {_y }}[\mathrm{i}]$ for $\mathrm{t}=1$. This has the benefit of avoiding double loops for $\mathrm{i}$ and $\mathrm{t}$ in our code, reserving the second dimension for combining several binary and continuous variable into one vector. It is easy to convert a two-dimensional array into two one-dimensional arrays using identities such as $y[i]<-y[i, 2]$ and $i_{-} y[i]<-y[i, 1]$ for all $i=1,2, \ldots, N$. Appendix B provides examples of different data formats and shows how the code can be extended for more than two points in time.

Following Bijak and Wiśniowski (2009), continuous dependent variables of the QSPVAR follow a multivariate normal distribution, and the precision matrix has an inverse 
Wishart distribution as prior. The parameterization of the inverse Wishart follows the standard uninformative prior, which commonly refers to a precision matrix equal to a scaled identity matrix. It should be noted that OpenBUGS uses precision matrices (i.e. the inverse of a covariance matrix) so that small values (low precision) translate into large variances signaling uninformative priors. Common practice is to assume when lacking prior knowledge that continuous dependent variables are uncorrelated under the prior distribution.

To account for binary dependent variables, we follow the multivariate probit model developed by Lunn et al. (2014), who also provide an OpenBUGS code. Consistent with Dueker (2005), the idea is to focus on the underlying random utility model (see equation (1)), which implies that latent variables follow a truncated normal distribution. Lunn et al. (2014) extend this principle by allowing several binary dependent variables, where their latent counterparts are drawn from a truncated multivariate normal distribution. This implies that these latent variables can be correlated, implying correlated binary variables. The main benefit of the latent variable model suggested by Lunn et al. (2014) is that it can be easily combined with several continuous dependent variables to derive the QSP-VAR.

Lunn et al. (2014) use the code $\mathrm{H} 1[i, j]<-\operatorname{step}(\operatorname{Psi1}[i, j])$, where Psi1 refers to the latent variable. The step function gives the value one if the latent variable is strictly positive and zero otherwise, capturing the relationship between the binary outcome, $\mathrm{H} 1[i, j]$, and the latent variable as described by equation (1). They use a multivariate normal distribution for latent variables as prior, $\operatorname{Psi1}[i, 1: Q] \sim \operatorname{dmnorm}(\operatorname{mu}[1: Q]$, $T[1: Q, 1: Q])$, and show that this prior, in combination with step functions, becomes truncated multivariate normal based on the standard sampling approach employed by OpenBUGS. Finally, the precision matrix is drawn from an inverted Wishart distribution, $\mathrm{T}[1: \mathrm{Q}, 1: Q] \sim \operatorname{dwish}(\mathrm{T} . \operatorname{matrix}[1: Q, 1: Q], Q)$. Here we adjust the code 
developed by Lunn et al. (2014) by combining the latent variables and continuous variables into one vector of variables following a multivariate normal prior distribution.

To implement the multivariate probit model, we need to address several methodological issues. In Lunn et al. (2014), $\mathrm{H} 1[i, j]$, the binary variable, is not observed directly, whereas in both Dueker's (2005) model and the QSP-VAR binary outcomes are observed. This creates a problem, as OpenBUGS does not allow any node to be both deterministic and observed. The step function, step $(\operatorname{Psi1}[i, j])$, is deterministic and hence the node, $\mathrm{H} 1[i, j]$, is deterministic by definition. So we need degenerate probability distributions, inducing OpenBUGS to treat the node as probabilistic when it is actually deterministic, as a certain event occurs with probability one (Lunn, Whittaker, \& Best, 2006).

Lunn et al. (2006) develop a degenerate distribution for probit models called dbern.aux(.). Degenerate distributions are not available in OpenBUGS, only in WinBUGS using the add-on 'Reversible Jump MCMC: WinBUGS Jump Interface' (Lunn, Best \& Whittaker, 2009; Lunn et al., 2006). WinBUGS and OpenBUGS are not fully compatible. Consequently, we develop our own degenerate distribution based on existing functions and distributions in OpenBUGS. Following Lunn et al. (2006), we create the degenerate Bernoulli distribution in OpenBUGS by first stating that the binary observed variable (e.g. position $\mathrm{y}_{1}$ written as $\mathrm{y} 1[i]$ ) follows a Bernoulli distribution with parameter, $\operatorname{pp} 1$, so that $y 1[i] \sim \operatorname{dbern}(\operatorname{pp} 1[i])$, and second stating that the parameter, pp1, in turn depends on the latent variable $\mathrm{y}_{1}{ }^{*}$ (written as y 1 star $\left.[i]\right)$ through a step function, which assigns the value one if the latent variable $\mathrm{y}_{1}{ }^{*}$ is strictly positive and zero otherwise, $\operatorname{pp} 1[i]<-$ step (y1star $[i])$. Accordingly, the binary observed variable and the latent variable are related as stated in equation (1). For instance, if the latent variable has a negative value, then the step function sets the parameter, pp1, equal to zero. Thus, the probability of 
observing a binary outcome of one is equal to zero. Evidently, the Bernoulli distribution is degenerate as the parameter, pp1, takes only two values, zero or one, making it deterministic. In using a multivariate approach, we need to arrange the variables into vectors and then specify multivariate normal distributions. Accordingly, the QSP-VAR combines continuous and binary dependent variables permitting an arbitrary correlation structure. The implementation of the QSP-VAR in OpenBUGS combines the Bayesian VAR model of Bijak and Wiśniowski (2009) for continuous multivariate time series and the multivariate probit model developed by Lunn et al. (2014). Extending Dueker's (2005) model using a multivariate probit approach based on Lunn et al. (2006, 2009) is useful, allowing latent variables to be correlated. However, Lunn et al. (2009) do not consider an autoregressive structure of latent variables, so we must modify the approach to incorporate a VAR(1) model in reduced form for latent variables.

The QSP-VAR requires sampling from multivariate distributions with mixed likelihoods, as latent variables are truncated normally distributed due to the step function linking latent variables to observed binary outcomes. Because of the inherent complexity of the model, computing time becomes an issue. After experimenting with various updating methods, a block hybrid updater seems to perform best (Wang, 2006). The following section highlights a specific-to-general specification approach for the QSP-VAR. Specific-to-general means that we start with a simple model and add complexity as opposed to starting with a complex (i.e. general) model (see Kennedy, 2003: 98). We recommend that researchers follow a similar route to select an appropriate degree of complexity. This ensures parsimonious models, reduced computation time and better convergence. 


\section{Demonstrating the QSP-VAR}

\section{Data and Variables}

To illustrate the QSP-VAR, we analyze positions, networks and performance in the context of the French corporate elite using data compiled by Maclean et al. (2014). In particular, we consider four initial positions: top executive $\left(\mathrm{y}_{1}\right)$, non-executive director $\left(\mathrm{y}_{2}\right)$, extra-corporate networker $\left(y_{3}\right)$, and entrepreneur with extensive ownership rights $\left(y_{4}\right)$. The third and fourth positions reflect external networks beyond the business sphere that are important in the French context (Denord, Lagneau-Ymonet, \& Thine, 2011; François, 2010; Pinçon \& PinçonCharlot, 1998; Stern \& Westphal, 2010). By construction, being an entrepreneur ( $\left.\mathrm{y}_{4}\right)$ does not change over time except by natural selection. Accordingly, we only consider the individual's initial decision to become an entrepreneur, whereas other positions can vary over time.

The sample is composed of agents active in the corporate world in the seven years between 1998 and 2004, a sufficiently long period to capture tenure (Zajac \& Westphal, 1996). To qualify for inclusion, agents must be a main board member of one of the top 100 French companies in 1998 , holding an executive $\left(\mathrm{y}_{1}\right)$ or non-executive $\left(\mathrm{y}_{2}\right)$ position, yielding a sample of 1,160 individuals. To select the top 100 French companies, we rank firms based on an equally-weighted index, which includes total capital employed, turnover, profit-beforetax, and employment (Grant, 1997). Five main sources (i.e. company reports, Le Guide des Etats Majors, Who's Who in France, web searches, newspapers and periodicals) provide information on individual agents. We apply a four-way classification for social class: upper, upper-middle, lower-middle, and lower class (Halsey, 1995), which captures social standing primarily through reference to parents' occupation supplemented by information on schooling, place of upbringing, and family circumstances (Bourdieu, 1987; 1996; Denord et al., 2011). Upper class (class_1) refers to those whose parents held leading positions in society or owned sizeable equity (more than 1\%) in top French companies. Upper-middle class (class_2) 
includes top professionals such as lawyers, doctors, engineers, senior state officials, and senior business people. Lower-middle class (class_3) was applied to white-collar occupations including teachers, sales people, lesser officials and technicians; while lower class (class_4) was reserved for parental occupations like worker, miner and van driver. The binary variable nation indicates whether agents are French nationals or not. Attendance at an elite school is captured by the dummy $E S$, whereas elite higher education refers to $E H$. Age in 1998 (age 98 ) and gender (gender) are coded. The number of top 100 company main board memberships and non-top 100 main board memberships held by an individual in 1998 and 2004 are recorded, but subsidiary board memberships are excluded. Non-top 100 French companies are included if classified as large companies by inclusion in Le Guide des Etats Majors. Likewise, the type and extent of engagement in external networks is noted, including involvement in charities, public bodies, business organizations, higher education, sports and culture. Overall network size is captured by the total number of corporate and extra-corporate board memberships $(N U M)$. The variable SIZE only focuses on the size of corporate networks. We use a proxy to assess the reach of networks, which refers to the number of different lifeworlds spanned by a network $(S P A N)$. To measure firm performance, we include return on assets $(R O A)$. Other measures such as return on equity or market to book ratios have been considered and lead to qualitatively similar results. Bloomberg provides these variables based on annual financial statements from 1995 to 2012. Appendix A provides definitions and coding schemes. We observe 391 agents at two points in time after discounting cases with missing data. To compare the three models, we use the same sample size. Firm performance is linked to individuals through their dominant position in an organization. For instance, if an individual is a CEO and a non-executive director elsewhere, the performance of the firm for which he or she serves as CEO is taken as prime. 


\section{Within-subject Correlation and Tenure}

We present three models following a specific-to-general approach. MODEL I only refers to positions, MODEL II includes measures of networks, and MODEL III adds performance. If MODEL I, which only includes binary dependent variables, does not confirm any significant correlations between positions, a multivariate probit approach would be obsolete, and it would be advisable to move to a univariate probit model. A more parsimonious model would reduce computation time and avoid over-specification.

Before modeling, it is useful to review some descriptive findings regarding agents' positions and tenure. Panel A of Table 1 compares initial positions in 1998 with positions in 2004, whereas Panel B considers movements between positions. In spite of a seven-year period, which is relatively long considering the average tenure of CEOs in the US and UK (Brookman \& Thistle, 2009), there is marked continuity in tenure; incumbents tending to be more entrenched in France. Many agents remain in at least one of the four positions. Agents can hold up to four positions simultaneously, and a significant number of agents operate in different spheres (Maclean et al., 2014; Maclean, Harvey \& Kling, 2015).

[Insert Table 1 here]

It is important to note that the QSP-VAR assumes stationarity. Non-stationarity occurs if properties of a variable such as mean, variance and autocorrelation structure change over time, leading to unreliable statistical inference (Kennedy, 2003). As the time dimension is short, it is difficult to test for time series issues such as non-stationarity (Binder et al., 2005). Hence researchers need to take care when including continuous variables that are known to be non-stationary (e.g. share prices). There are several methods to deal with nonstationarity such as working with first-differenced data $\Delta y_{i t}$, i.e. $y_{i t-} y_{i t-1}$. Using the change in a variable or growth rates can ensure stationarity; however, a larger time dimension (e.g. several waves of data collection) is needed. 
Given the short time dimension, we do not consider agent-specific fixed or randomeffects, since including 391 dummies, one for each agent (excluding the constant term), would be likely to over-specify the model. Researchers with access to longer time dimensions might consider agent-specific effects to capture unobserved characteristics. In this case, the approach needs to be modified, as fixed or random effects and lagged dependent variables are not independent. The literature discusses different approaches, including Helmert's transformation and dynamic panel data estimators (Arellano \& Bover, 1995; Kling, 2005). These methods can be also used in panel VARs (Canova \& Ciccarelli, 2013).

It is advisable to commence with a simple model (MODEL I) that only captures initial positions, current positions and a set of exogenous variables (e.g. gender). Exogenous variables, which Maclean et al. (2014) call 'variables of fate', were determined long before an agent ascended to her first position. 'Variables of fate' might explain initial positions, which in turn can affect current positions. MODEL I refers to a QSP-VAR with only binary dependent variables. In particular, MODEL I permits latent variables that are correlated to be captured by the multivariate probit part of the model (Lunn et al., 2014). After running MODEL I, researchers can determine contemporaneous correlations between latent variables.

To prevent starting values and poor convergence from affecting posterior distributions, the first 1000 iterations are discarded (Gelman \& Shirley, 2011). We run 5000 additional iterations, and tables provide the 2.5 and 97.5 percentiles of posterior distributions. Hence we obtain credibility intervals for parameters, providing more information than null hypotheses testing (Zyphur \& Oswald, 2015). Additional information such as Monte Carlo standard errors of the mean indicate a high level of precision (Roberts, 1996). Table 2 provides the results for MODEL I.

[Insert Table 2 here] 
The interpretation of Table 2 can focus on null hypothesis testing using the duality principle. Hence, if zero is not in the range of values described by the 2.5 and 97.5 percentiles, we can reject the null hypothesis that the parameter is equal to zero (i.e. the covariate has a significant impact). Alternatively, we can refer to a direct inference that considers whether the effect is practically meaningful or of 'economic significance' (McCloskey \& Ziliak, 1996; Zyphur \& Oswald, 2015). We can see that occupying a position of CEO in 2004 is positively influenced by holding a similar position in $1998\left(\mathrm{y}_{1}{ }^{*}\right)$, having external board memberships $\left(\mathrm{y}_{2}{ }^{*}\right)$, and being an entrepreneur $\left(\mathrm{y}_{4}{ }^{*}\right)$. Social class in the form of higher social status impacts on initial positions when the agent concerned is an extra-corporate networker or nonexecutive corporate director (Smith, Menon, \& Thompson, 2012). Elite schooling and higher education enhance the chances of becoming a corporate or extra-corporate networker. Accordingly, there is clear evidence of within-subject correlation since past latent variables exhibit considerable impact on current values. Finally, we determine correlation coefficients between latent variables. The median of the correlation coefficient between $\mathrm{y}_{1}{ }^{*}$ and $\mathrm{y}_{3}{ }^{*}$ is 0.450 with a $95 \%$ credibility interval from 0.235 to 0.665 , confirming that a multivariate probit approach is required.

\section{Making Agents' Networks Endogenous}

To investigate the role of networks, MODEL II uses the full potential of the QSP-VAR by incorporating continuous dependent variables to account for different types of networks. Table 3 presents the results. First, we consider the size of an agent's corporate network measured by board memberships, which create interlocks between firms when agents serve on multiple boards. The variable SIZE captures the extent of an agent's corporate network in terms of the number of ties. Second, the variable $N U M$ indicates the number of corporate and extra-corporate networks; thus quantifying the magnitude of both types of networks. Third, 
the variable SPAN refers to the number of life-worlds an agent is involved in at the highest level, capturing involvement in politics, charities, culture and other spheres.

We run 2000 iterations using the Gibbs sampler with two chains to check for convergence. Convergence is achieved as the chains approach similar values for parameters. In line with Gill (2008), we determine the potential scale reduction factor (PSRF), defined as the total variance across chains divided by the pooled variance within chains (Gelman \& Rubin, 1992; Gelman et al., 1995). Following Brooks and Gelman (1998), we modify PSFR and calculate the measure for different numbers of iterations. Figure 2 shows a trace plot for parameter $b[3]$, which refers to the covariate $\mathrm{y}_{2 \mathrm{it}-1}{ }^{*}$, the latent variable for a corporate networker in 1998. The trace plot indicates convergence of the two chains after about 1500 iterations, since both chains reach a target distribution. Figure 2 also plots the modified PSFR for parameter $b[2]$ and the constant term $b[1]$ for an increasing number of iterations. It is evident that the PSFR (red line) approaches one, which is below the recommended value of 1.2 (Cowles \& Carlin, 1996; Brooks \& Roberts, 1998).

[Insert Figure 2 here]

MODEL II is more complex and requires a burn-in period of 2,000 to ensure convergence (see Figure 2). We discard these initial iterations and conduct 10,000 iterations to obtain posterior distributions. Table 3 reports medians of estimated parameters. A star $(*)$ indicates whether the $95 \%$ credibility interval contains zero, indicating statistical significance (i.e. whether the parameter is significantly different from zero). It is important to stress that the QSP-VAR treats binary and continuous variables as dependent variables within the terms of a vector autoregression. Hence the three continuous measures of networks are affected by other lagged dependent variables, making network formation endogenous.

Table 3 confirms a strong pattern of interrelationships between the three current positions, re-emphasizing the results of MODEL I presented in Table 2. There is clear 
evidence in all three specifications that previous positions have an impact on current positions, indicative of within-subject correlation. Furthermore, CEOs are more likely to remain in power if they have been corporate networkers. For the initial period, where the 'variables of fate' act on initial positions and networks, it is evident that social class matters in becoming either a corporate or an extra-corporate networker. Regarding the impact of networks on tenure, it is evident that in all three specifications past networks do not determine current positions. In fact, there is even a slightly negative impact of the size of all networks $(N U M)$ on remaining in the role of an extra-corporate networker. Furthermore, networks are clearly not exogenous, as social class, nationality and age affect the size and range of corporate and extra-corporate networks (Palmer \& Maher, 2005).

\section{[Insert Table 3 here]}

The most significant strength of the QSP-VAR is its ability to capture complex interrelationships and indicate causal order. Hence researchers can test much more sophisticated hypotheses, which are beyond the reach of conventional methods. To illustrate the strength of the QSP-VAR, Table 4 shows standard probit models, where current positions can be explained by the three measures of networks. These standard probit models assume that measures for the size and reach of networks are exogenous, revealing that networks explain whether agents remain at the top of the game (i.e. maintain their CEO position). Even after controlling for initial positions some measures for extra-corporate networks (NUM and $S P A N)$ remain highly significant. By making networks endogenous, driven by agents' characteristics and initial positions, the QSP-VAR can distinguish between spurious correlations and causality, in the sense of Granger causality. Hence, the QSP-VAR uncovers whether past (and unchangeable) characteristics (e.g. gender, social class) are hidden drivers of network creation, which in turn through the formation of networks affect other variables 
such as positions. Put differently, finding a correlation between networks and positions (see Table 4) might be actually caused by an agent's characteristics as shown in Table 3.

[Insert Table 4 here]

\section{Positions, Networks and Performance}

MODEL III considers the impact of firm performance on executive tenure, and whether tenure in turn impinges on performance. We consider three measures of firm performance: return on assets (ROA), return on equity (ROE), and market to book ratios (MTB). We only report our findings based on ROA as other measures lead to qualitatively similar results. The QSP-VAR can test whether past performance influences current position, and in addition treats firm performance as a dependent variable explained by executive tenure and networks.

In a standard model with firm performance as the dependent variable but without lagged firm performance as covariate, industry or firm-specific effects can be modeled using fixed or random effects. However, the QSP-VAR includes lagged dependent variables as covariates making the use of fixed or random effects problematic. If there is a time-invariant industry or firm-specific effect, then both current and past performance are affected by it. By using past performance to explain current performance, endogeneity problems arise. It is possible to overcome this problem using dynamic panel data estimation (Arellano \& Bover, 1995) and Helmert's transformation (Kling, 2005).

In line with MODEL II, the burn-in period is 2,000 to ensure convergence. We discard these initial iterations and conduct 10,000 iterations. As indicated in previous models, agents derive benefit from holding positions as corporate and extra-corporate networkers, which increase executive durability. Table 5 reports the findings based on the three measures of network size and range used in MODEL II. The findings are consistent with MODEL I, as there is clear evidence that remaining at the top of the game depends on having been a 
corporate networker in the past. Remaining in post as a corporate networker in turn depends on holding extra-corporate positions. These interrelationships between positions dominate. In addition, ascending to initial command posts is mainly driven by agents' characteristics (e.g. age, gender) and, above all, by higher social class. Moreover, Table 5 confirms our previous findings based on MODEL II (see Table 4), as various measures of the size and range of networks do not add explanatory power; they are endogenous and explained by agents' 'variables of fate'. Finally, Table 5 shows that past firm performance does not threaten CEOs' tenure directly. However, there is evidence that strong performance stabilizes corporate and to a limited extent extra-corporate networks, which in turn affects CEO tenure. We do not find evidence that firm performance is enhanced by agents' positions or networks. These findings confirm that the QSP-VAR is a valuable tool for identifying complex dynamic relationships between positions, networks and firm performance.

[Insert Table 5 here]

\section{Discussion}

The QSP-VAR is a flexible tool ideal for analyzing longitudinal data with binary and continuous variables. The unique feature of the QSP-VAR is that it permits more than one binary outcome, and binary variables can be correlated. Given its autoregressive structure, within-subject correlation, the impact of past variables on current variables, can be studied. Hence, the QSP-VAR can test the causal order of variables, making it unnecessary to specify dependent or independent variables prior to analyzing the data. By assuming a Bayesian approach, the QSP-VAR can handle longitudinal studies with small time dimensions and a limited number of cross-sectional observations. Furthermore, priors can be made informative using expert opinions available in some areas of research. To enable use of the QSP-VAR by other organizational researchers, Appendix B provides our OpenBUGS code. 
Ballinger (2004), Braun, Kuljanin and DeShon (2013) and Ketchen, Boyd and Bergh (2008) have noted an increasing interest in the application of longitudinal research designs in strategic and organizational research. Longitudinal methods, for example, are particularly appropriate for studying the evolution of social networks (Gulati, 1995; Kijkuit \& van den Ende, 2010; Mizruchi \& Stearns, 1988; Paquin \& Howard-Grenville, 2013) and the exploitation of social capital (Borgatti, Brass \& Halgin, 2014; Borgatti, Mehra, Brass \& Labianca, 2009). Researchers interested in binary decisions, such as those relating to staff turnover, could gain additional insights through application of the QSP-VAR. In particular, the analysis of decision paths (including searches for job alternatives, the evaluation of alternatives, and exit), in which binary choices occur in a sequential order, is an ideal research setting for the QSP-VAR (Lee \& Mitchell, 1994). Within the strategy domain, in which 'the ubiquity of cross-sectional designs makes it difficult to generalize into and about dynamic relationships among strategy, execution and performance' (Ketchen et al., 2008: 655), the QSP-VAR could be used in longitudinal studies to quantify the impact of past decisions on subsequent decisions, responding to the evident need for more attention to be paid to issues of 'statistical power, construct measurement, and causality' (Ketchen et al., 2008: 649). Continuous dependent variables such as team performance could readily be incorporated in such studies (Delarue et al., 2008; Mehra, Smith, Dixon, \& Robertson, 2006). The QSP-VAR, for example, could indicate whether past team performance leads to turnover or whether, on the contrary, past turnover affects team performance. It could identify whether both effects exist simultaneously and assess their relative importance.

We have demonstrated the QSP-VAR by analyzing relationships between top executive tenure, networks, and firm performance. The literature tends to treat either tenure or performance as dependent variables, overlooking the problem of causal order. Moreover, the literature argues that networks influence performance through interlocks (Geletkanycz \& 
Boyd, 2011; Mizruchi, 1996; Shropshire, 2010). As agents themselves elect to form networks, it is reasonable to assume that they should also personally derive benefit from them (Burt et al., 2000; Geletkanycz et al., 2001; Geletkanycz, \& Hambrick, 1997; Zaheer et al., 2010). Networks themselves are not necessarily exogenous, as they are formed by combining positions. The QSP-VAR reveals causal order. Our findings show that it is agents' positions that comprise the dominant force. Networks are driven by the positions and characteristics of individual agents. Agents' initial positions can be explained mainly by their individual characteristics: social class, namely higher social status, being the dominant factor governing the emergence of corporate and extra-corporate networkers (McPherson, Smith-Lovin \& Cook, 2001; Smith et al., 2012; Stern \& Westphal, 2010). We find that in France underperformance does not affect CEO tenure directly, but it does undermine an individual's capacity to serve as a corporate networker, and to a lesser extent extra-corporate networker. In the context of research on the durability of corporate elites, these are important findings, helping to paint a much richer picture of the functioning of the French national business system, especially in pointing to the continuing importance of class and the pivotal role of extra-corporate networks to survivorship, enabling some agents to retain their positions far longer than might typically apply in the UK or US (Maclean et al., 2014). Without the QSPVAR such theoretically interesting relationships would remain hidden from view.

The QSP-VAR has limitations. Most importantly, we assume homogeneity, as individual fixed or random effects are not considered. It is not advisable to include fixed or random effects in the QSP-VAR due to the autoregressive structure of the model. Hence, fixed or random effects and lagged dependent variables will be correlated. Applying a Helmert's transformation (i.e. future mean-differencing) or alternatively dynamic panel data estimators could address this issue (Arellano \& Bover, 1995; Kling, 2005). Yet these methods have never been used in the context of binary dependent variables, highlighting the need for 
further research. In general, the QSP-VAR can be extended to incorporate additional effects. For instance, one could add other latent variables (such as the quality of networks) with adequate measurement models. Finally, the QSP-VAR is a VAR in reduced form in line with Dueker's (2005) QVAR; therefore, dual-causality (i.e. simultaneity) where variables affect each other at the same time is not considered. The QSP-VAR could be extended to a structural VAR by applying Cholesky decomposition as in standard VAR models. By providing a users' guide to building a QSP-VAR, we have gone some way towards overcoming the 'lack of familiarity by organizational researchers' in the context of Bayesian analysis highlighted by Zyphur and Oswald (2015: p.1).

\section{Conclusion}

The primary contribution of this paper is to add to the arsenal of analytical methods deployed in longitudinal studies. Much organizational research is bedeviled by problems of the type we have considered here with respect to the durability of the French corporate elite, particularly with regard to establishing causal order when combining binary and continuous dependent variables in short time dimension research. The power of the Bayesian QSP-VAR lies in its capacity to disentangle and make sense of complex interrelationships, revealing how social systems operate in practice without the necessity of crystal ball gazing in search of directly and indirectly observable relationships between variables. Our approach chimes well with the call made by Davis (2010: p.706) in this journal for organization science to cast off its selflimiting obsession with a narrow range of theories and to search more expansively for "the social mechanisms [that] are the cogs and wheels of theoretical explanations", going beyond "laundry-list regressions" to distinguish between "reflective and formative indicators" and explain the underlying processes that animate the social world. 


\section{Acknowledgements}

We wish to thank the Editor, James LeBreton, the Associate Editor, Brian Boyd, and two anonymous referees for their most helpful comments. Without their efforts, our QSP-VAR would not have reached its full potential. We had the benefit of advice on our OpenBUGS code from Dave Lunn, one of the developers of WinBUGS / OpenBUGS for which we are grateful. Sadly, when we sought advice from Michael Dueker, who devised the QVAR and whose work inspired our own, we learned that he had passed away on 29th January 2015. Dueker's research has had a significant impact in economics, econometrics and related disciplines. We dedicate this paper to him in recognition of his many pioneering achievements.

\section{Biographies}

Gerhard Kling is Professor of International Business and Management at SOAS University of London. He studied economics and mathematics and holds a PhD in Economics from the University of Tuebingen. His research focuses on quantitative research methods with applications in management and finance. His recent publications are in Organization Studies, the British Journal of Management and the International Journal of Research in Marketing.

Charles Harvey is Professor of Business History and Management at Newcastle University Business School. He holds a PhD in International Business from the University of Bristol. He is author of numerous books and articles in the fields of strategy, leadership and management. His research focuses upon the historical processes that inform contemporary business practice, entrepreneurial philanthropy, and the exercise of power by elite groups in society. His recent publications are in the Academy of Management Review, Organization Studies, Organization, Human Relations, and the Business History Review. 
Mairi Maclean is Professor of International Management and Organisation Studies at Newcastle University Business School, where she is Director of Research. She received her $\mathrm{PhD}$ from the University of St Andrews. Her research interests include international business elites and elite power, entrepreneurial philanthropy, and history and organisation studies. She is the author of four books, including Business Elites and Corporate Governance in France and the UK (Palgrave Macmillan, 2006) with Charles Harvey and Jon Press, and editor of a further four. Recent publications include contributions to the Academy of Management Review, Organization Studies, Human Relations, Organization, and the Business History Review. 


\section{References}

Adams, R.B., Almeida, H., \& Ferreira, D. (2005). Powerful CEOs and their impact on corporate performance. The Review of Financial Studies, 18, 1403-1432.

Ahuja, G. (2000). Collaboration networks, structural holes and innovation: A longitudinal study. Administrative Science Quarterly, 45, 425-455.

Albert, A., \& Anderson, J.A. (1984). On the existence of maximum likelihood estimates in logistic regression models. Biometrika, 71, 1-10.

Allgood, S., \& Farrell, K.A. (2000). The effect of CEO tenure on the relation between firm performance and turnover. Journal of Financial Research, 23, 373-390.

Arellano, M., \& Bover, O. (1995). Another look at the instrumental variable estimation of error-component models. Journal of Econometrics, 10, 29-51.

Ballinger, G.A. (2004). Using generalized estimating equations for longitudinal data analysis. Organizational Research Methods, 7, 127-150.

Bateman, T.S., \& Organ, D.W. (1983). Job satisfaction and the good soldier: The relationship between affect and employee citizenship. Academy of Management Journal, 26, 587595.

Bijak, J., \& Wiśniowski, A. (2009). Forecasting of immigration flows until 2025 for selected European countries using expert information. IDEA Working Paper.

Binder, M., Hsiao, C., \& Pesaran, M.H. (2005). Estimation and inference in short panel vector autoregressions with unit roots and cointegration. Econometric Theory, 21, $795-837$.

Bliese, P.D., Chan, D., \& Ployhart, R.E. (2007). Multilevel methods: Future directions in measurement, longitudinal analyses, and non-normal outcomes. Organizational Research Methods, 10, 551-563. 
Bliese, P.D., \& Ployhart, R.E. (2002). Growth modeling using random coefficient models: Model building, testing, and illustrations. Organizational Research Methods, 5, 362387.

Bollen, K.A., \& Pearl, J. (2013). Eight myths about causality and structural equation models. In: Handbook of Causal Analysis for Social Research, Morgan, S.L. (ed.), 301-328.

Borgatti, S.P., Brass, D.J., \& Halgin, D.S. (2014). Social network research: Confusions, criticisms, and controversies. In: Contemporary perspectives on organizational social networks, Brass, D.J., Labianca, G., Mehra, A., Halgin, D.S., \& Borgatti, S.P. (eds.), Bingley: Emerald Books, 1-32.

Borgatti, S.P., Mehra, A., Brass, D.J., \& Labianca, G. (2009). Network analysis in the social sciences, Science, 323, 892-895.

Bourdieu, P. (1987). What makes a social class? On the theoretical and practical existence of groups. Berkeley Journal of Sociology, 32, 1-17.

Bourdieu, P. (1996). The state nobility: Elite schools in the field of power. Cambridge: Polity.

Boyd, B.K. (1995). CEO duality and firm performance: A contingency model. Strategic Management Journal, 16, 301-312.

Braun, M.T., Kuljanin, G., \& DeShon, R.P. (2013). Spurious results in the analysis of longitudinal data in organizational research. Organizational Research Methods, 16, 302-330.

Brickley, J.A. (2003). Empirical research on CEO turnover and firm-performance: A discussion. Journal of Accounting and Economics. 36, 227-233.

Brookman, J., \& Thistle, P. (2009). CEO tenure, the risk of termination and firm value. Journal of Corporate Finance, 15, 331-344. 
Brooks, S.P., \& Gelman, A. (1998). Alternative methods for monitoring convergence of iterative simulations. Journal of Computational and Graphical Statistics, 7, 434-455.

Brooks, S.P., \& Roberts, G.O. (1998). Assessing convergence of Markov Chain Monte Carlo algorithms. Statistics and Computing, 8, 319-335.

Burt, R.S. (1980). Cooptive corporate actor networks: A reconsideration of interlocking directorates involving American manufacturing. Administrative Science Quarterly, $25,557-582$.

Burt, R.S., Hogarth, R.M., \& Michaud, C. (2000). The social capital of French and American managers. Organization Science, 11, 123-147.

Canova, F., \& Ciccarelli, M. (2013). Panel vector autoregressive models: A survey. Advances in Econometrics, 32, 205-246.

Cao, Q., Maruping, L.M., \& Takeuchi, R. (2006). Disentangling the effects of CEO turnover and succession on organizational capabilities: A social network perspective. Organization Science, 17, 563-576.

Chan, D. (1998). The conceptualization and analysis of change over time: An integrative approach incorporating longitudinal mean and covariance structures analysis (LMACS) and multiple indicator latent growth modeling (MLGM). Organizational Research Methods, 1, 421-483.

Chan, D., \& Schmitt, N. (2000). Interindividual differences in intraindividual changes in proactivity during organizational entry: A latent growth modeling approach to understanding newcomer adaptation. Journal of Applied Psychology, 85, 190-210.

Cowles, M.K., \& Carlin, B.P. (1996). Markov Chain Monte Carlo convergence diagnostics: A comparative review. Journal of the American Statistical Association, 91, 883-904.

Dai, B., Ding, S., \& Wahba, G. (2013). Multivariate Bernoulli distribution, Bernoulli, 19, 1465-1483. 
Daily, C.M. \& Johnson, J.L. (1997). Sources of CEO power and firm financial performance: A longitudinal assessment. Journal of Management, 23, 97-117.

Dalton, D.R., \& Kesner, I.F. (1985). Organizational performance as an antecedent of inside/outside chief executive succession: An empirical assessment. Academy of Management Journal, 28, 749-762.

Datta, D.K., \& Rajagopalan, N. (1998). Industry structure and CEO characteristics: An empirical study of succession events. Strategic Management Journal, 19, 833-852.

Davis, G.F. (2010). Do theories of organizations progress? Organizational Research Methods, 13, 690-709.

DeFond, M.L. \& Park, C.W. (1999). The effect of competition on CEO turnover. Journal of Accounting and Economics, 27, 35-56.

Delarue, A., Van Hootegem, G., Procter, S., \& Burridge, M. (2008). Teamworking and organizational performance: A review of survey-based research. International Journal of Management Reviews, 10, 127-148.

Denord, F., Lagneau-Ymonet, P., \& Thine, S. (2011). Le champ du pouvoir en France. Actes de la Recherche en sciences sociales, 190, 24-57.

Dueker, M. (2005). Dynamic forecasts of qualitative variables: A Qual VAR model of U.S. recessions. Journal of Business \& Economic Statistics, 23, 96-104.

Eichengreen, B., Watson, M. W., \& Grossman, R.S. (1985). Bank rate policy under the interwar gold standard. Economic Journal, 95, 725-745.

François, P. (2010). Les guépards du capitalisme français? Structure de l'élite patronale et modes d'accès aux positions dominantes. Paper presented at 'Les élites économiques en France et en Europe', DRM-IRISSO, Paris-Dauphine. 
Friedman, S.D., \& Singh, H. (1989). CEO succession and stockholder reaction: The influence of organizational context and event content. Academy of Management Journal, 32, 718-744.

Geletkanycz, M.A. \& Boyd, B.K. (2011). CEO outside directorships and firm performance: A reconciliation of agency and embeddedness views. Academy of Management Journal, 54, 335-352.

Geletkanycz, M.A., Boyd, B.K. \& Finkelstein, S. (2001). The strategic value of CEO external directorate networks: Implications for CEO compensation. Strategic Management Journal, 22, 889-898.

Geletkanycz, M.A., \& Hambrick, D.C. (1997). The external ties of top executives: Implications for strategic choice and performance. Administrative Science Quarterly, $42,654-681$.

Gelman, A., Carlin, J.B., Stern, H.S., \& Rubin, D.B. (1995). Bayesian data analysis. London: Chapman and Hall.

Gelman, A., Jakulin, A., Pittau, M.G., \& Su, Y-S. (2008). A weakly informative default prior distribution for logistic and other regression models. Annals of Applied Statistics, 2, $1360-1383$.

Gelman, A., \& Rubin, D.B. (1992). Inference from iterative simulation using multiple sequences. Statistical Science, 7, 457-511.

Gelman, A., \& Shirley, K. (2011). Inference from simulations and monitoring convergence. In: Handbook of Markov Chain Monte Carlo, Brooks, S.P., Gelman, A., Jones, G., \& Meng, X-L. (eds.), Boca Raton, FL: Chapman Hall, 163-174.

Gill, J. (2008). Bayesian methods: A social and behavioral science approach. 2nd ed. Boca Raton, FL: Chapman \& Hall. 
Goyal, V.K., \& Park, C.W. (2002). Board leadership structure and CEO turnover. Journal of Corporate Finance, 8, 49-66.

Granger, C.W.J. (1969). Investigating causal relations by econometric models and crossspectral methods. Econometrica, 37, 424-438.

Grant, R.R. (1997). Measuring corporate power: Assessing the options. Journal of Economic Issues, 31, 453-460.

Gregory-Smith, I., Thompson, S., \& Wright, P.W. (2009). Fired or retired? A competing risks analysis of chief executive turnover. The Economic Journal, 119, 463-481.

Gulati, R. (1995). Social structure and alliance formation patterns: A longitudinal analysis. Administrative Science Quarterly, 40, 619-652.

Gulati, R., \& Srivastava, B. (2014). Bringing agency back into network research: Constrained agency and network action. In: Contemporary perspectives on organizational social networks, Brass, D.J., Labianca, G., Mehra, A., Halgin, D.S. \& Borgatti, S.P. (eds.) Bingley: Emerald Books, 73-94.

Halsey, A.H. (1995). Change in British society, 4th ed. Oxford: OUP.

Hambrick, D.C., \& Fukutomi, G.D.S. (1991). The seasons of a CEO's tenure. Academy of Management Review, 16, 719-742.

Harrison, D.A., \& Hulin, C.L. (1989). Investigations of absenteeism: Using event-history models to study the absence-taking process. Journal of Applied Psychology, 74, 300316.

Hassett, M.E., \& Paavilainen-Mäntymäki, E. (2013). Handbook of Longitudinal Research Methods in Organisation and Business Studies, Cheltenham: Edward Elgar.

Haveman, H.A., \& Nonnemaker, L. (2000). Competition in multiple geographic markets: The impact on growth and market entry. Administrative Science Quarterly, 45, 232-267. 
Henderson, A.D., Miller, D., \& Hambrick, D.C. (2006). How quickly do CEOs become obsolete? Industry dynamism, CEO tenure, and company performance. Strategic Management Journal, 27, 447-460.

Hsiao, C. (2014) Analysis of panel data, $2^{\text {nd }}$ ed., Cambridge University Press.

Kennedy, P. (2003). A guide to econometrics. 5th ed., MIT Press.

Kenny, D.A. (1975). Cross-lagged panel correlation: A test for spuriousness. Psychological Bulletin, 82, 887-903.

Ketchen, D.J., Boyd, B.K. \& Bergh, D.D. (2008). Research methodology in strategic management: Past accomplishments and future challenges. Organizational Research Methods, 11, 643-658.

Kijkuit, B., \& van den Ende, J. (2010). With a little help from our colleagues: A longitudinal study of social networks. Organization Studies, 31, 451-479.

Kling, G. (2005). The impact of trading mechanisms and stock characteristics on order processing and information costs: A panel GMM approach. Economics Bulletin, 7, $1-11$.

Lee, T.W., \& Mitchell, T.R. (1994). An alternative approach: The unfolding model of voluntary employee turnover. Academy of Management Review, 19, 51-89.

Liebowitz, S.J., \& Margolis, S.E. (1995). Path dependence, lock-in and history. Journal of Law and Economics, 11, 205-226.

Liang, K.-Y., \& Zeger, S.L. (1986). Longitudinal data analysis using generalized linear models. Biometrika, 73, 13-22.

Lubatkin, M., Chung, K., Rogers, R., \& Owers, J. (1989). Stockholder reactions to CEO change in large organizations. Academy of Management Journal, 32, 47-68.

Lunn, D. J., Best, N., \& Whittaker, J.C. (2009). Generic reversible jump MCMC using graphical models. Statistics and Computing, 19, 395-408. 
Lunn, D.J., Osorio, C., \& Whittaker, J.C. (2014). A multivariate probit model for inferring missing haplotype/genotype data. Working Paper.

Lunn, D. J., Whittaker, J.C., \& Best, N. (2006). A Bayesian toolkit for genetic association studies. Genetic Epidemiology, 30, 231-247.

Maclean, M., Harvey, C., \& Chia, R. (2010). Dominant corporate agents and the power elite in France and Britain. Organization Studies, 31, 327-348.

Maclean, M., Harvey, C., \& Kling, G. (2014). Pathways to power: Class, hyper-agency and the French corporate elite. Organization Studies, 35, 825-855.

Maclean, M., Harvey, C., \& Kling, G. (2015). Business elites and the field of power in France. Research in the Sociology of Organizations, 43, 189-219.

Marcel, J.J., Cowen, A.P., \& Ballinger, G.A. (2013). Are disruptive CEO successions viewed as a governance lapse? Evidence from board turnover. Journal of Management, forthcoming.

McCloskey, D.N., \& Ziliak, S.T. (1996). The standard error of regressions. Journal of Economic Literature, 34, 97-114.

McPherson, M., Smith-Lovin, L., \& Cook, J.M. (2001). Homophily in social networks. Annual Review of Sociology, 27, 415-444.

Mehra, A., Dixon, A.L., Brass, D.J., \& Robertson, B. (2006). The social network ties of group leaders: Implications for group performance and leaders reputation. Organization Science, 17, 64-79.

Mehra, A., Smith, B., Dixon, A.L., \& Robertson, B. (2006). Distributed leadership in teams: The network of leadership perceptions and team performance. Leadership Quarterly, $17,232-245$.

Mills, C.W. (1956). The power elite. Oxford: Oxford University Press. 
Mizruchi, M.S. (1996). What do interlocks do? An analysis, critique, and assessment of research on interlocking directorates. Annual Review of Sociology, 22, 271-298.

Mizruchi, M.S., \& Stearns, L.B. (1988). A longitudinal study of the formation of interlocking directorates. Administrative Science Quarterly, 33, 194-210.

Ocasio, W. (1994). Political dynamics and the circulation of power: CEO succession in U.S. industrial corporations 1960-1990. Administrative Science Quarterly, 29, 285-312.

Paquin, R.L., \& Howard-Grenville, J. (2013). Blind dates and arranged marriages: Longitudinal processes of network orchestration. Organization Studies, 34, 16231653.

Palmer, D., \& Maher, M. (2005). The managerial revolution revisited: The moderating impact of top managers' social class position. Strategic Organization, 3, 385-430.

Pérez-González, F. (2006). Inherited control and firm performance. American Economic Review, 96, 1559-1588.

Pettigrew, A. (1990). Longitudinal field research on change: Theory and practice. Organization Science, 1, 267-292.

Pinçon, M., \& Pinçon-Charlot, M. (1998). Grandes fortunes: Dynasties familiales et formes de richesse en France. Paris: Payot.

Ployhart, R.E., \& Hakel, M.D. (1998). The substantive nature of performance variability: Predicting interindividual differences in intraindividual performance. Personnel Psychology, 51, 859-901.

Ployart, R.E., \& Vandenberg, R.J. (2010). Longitudinal research: The theory, design, and analysis of change. Journal of Management, 36, 94-120.

Porter, L.W., Steers, R.M., Mowday, R.T., \& Boulian, P.V. (1974). Organizational commitment, job satisfaction and turnover among psychiatric technicians. Journal of Applied Psychology, 58, 603-609. 
Rechner, P.L., \& Dalton, D.R. (1991). CEO duality and organizational performance: A longitudinal analysis. Strategic Management Journal, 12, 155-160.

Rogosa, D. (1980). A critique of cross-lagged correlations. Psychological Bulletin, 88, 245258.

Roberts, G.O. (1996). Markov Chain concepts related to sampling algorithms. In: Markov Chain Monte Carlo in Practice, Gilks, W.R., Richardson, S., \& Spiegelhalter, D.J. (eds.): Chapman and Hall, London, UK, 45-58.

Schonfeld, I.S., \& Rindskopf, D. (2007). Hierarchical linear modeling in organizational research: Longitudinal data outside the context of growth modeling. Organizational Research Methods, 10, 417-429.

Shen, W., \& Cannella, A.A. (2002). Revisiting the performance consequences of CEO succession: The impacts of successor type, post succession senior executive turnover, and departing CEO tenure. Academy of. Management Journal, 45, 717-733.

Shropshire, C. (2010). The role of the interlocking director and board receptivity in the diffusion of practices. Academy of Management Review, 35, 246-264.

Sims, C.A. (1972). Money, income, and causality. American Economic Review, 62, 540-552.

Sims, C.A. (1980a). Macroeconomics and reality. Econometrica, 48, 1-48.

Sims, C.A. (1980b). Comparison of interwar and postwar business cycles: Monetarism reconsidered. American Economic Review, 70, 250-257.

Smith, E.B., Menon, T., \& Thompson, L. (2012). Status differences in the cognitive activation of social networks. Organization Science, 23, 67-82.

Stern, I., \& Westphal, J.D. (2010). Stealthy footsteps to the boardroom: Executives' backgrounds, sophisticated interpersonal influence behaviour, and board appointments. Administrative Science Quarterly, 55, 278-319. 
Taris, T.W. (2013). Nonresponse in longitudinal research: Charting the terrain. In: Handbook of Longitudinal Research Methods in Organisation and Business Studies, Hassett, M.E., \& Paavilainen-Mäntymäki, E. (eds.), Cheltenham: Edward Elgar: 23-32.

Useem, M., \& Karabel, J. (1986). Pathways to top corporate management. American Sociological Review, 51, 184-200.

Wang, J. (2006). Bayesian computational techniques for inverse problems in transportation processes. Dissertation.

Willett, J.B. (1989). Some results on reliability for the longitudinal measurement of change: Implications for the design of studies of individual growth. Educational and Psychological Measurement, 49: 587-602.

Zaheer, A., Gözübüyük, R., \& Milanova, H. (2010). It's the connections: The network perspective in interorganizational research. Academy of Management Perspectives, $24,62-77$.

Zajac, E.J. (1990). CEO selection, succession, compensation and firm performance: A theoretical integration and empirical analysis. Strategic Management Journal, 11, 217-230.

Zajac, E.J., \& Westphal, J.D. (1996). Director reputation, CEO board power, and the dynamics of board interlocks. Administrative Science Quarterly, 41, 507-529.

Zeger, S.L., Liang, K-Y., \& Albert, P.S. (1988). Models for longitudinal data: A generalized estimating equation approach. Biometrics, 44, 1049-1060.

Zorn, C. (2005). A solution to separation in binary response models. Political Analysis, 13, 157-170.

Zyphur, M.J., \& Oswald, F.L. (2015). Bayesian estimation and inference: A user's guide. Journal of Management, 41, 390-420. 


\section{Footnotes}

${ }^{1}$ If the error term were drawn from an extreme value distribution, it would imply a logistic model.

${ }^{2}$ Weak exogeneity means that lagged variables, e.g. $\mathrm{z}_{\mathrm{it}-1}$, and current error terms $\mathrm{u}_{\mathrm{it}}$ are uncorrelated. This is a sufficient condition to ensure unbiased estimates. Note that we do not require that current variables, e.g. $\mathrm{z}_{\mathrm{i}}$, and current error terms $\mathrm{u}_{\mathrm{it}}$ are uncorrelated. So by lagging variables weak exogeneity can be assured.

${ }^{3}$ The default uninformative prior is a normal distribution with mean zero and precision 1.0E-6. Precision refers to the inverse of the variance, which is standard in OpenBUGS. 
Figure 1: Illustration of the problem

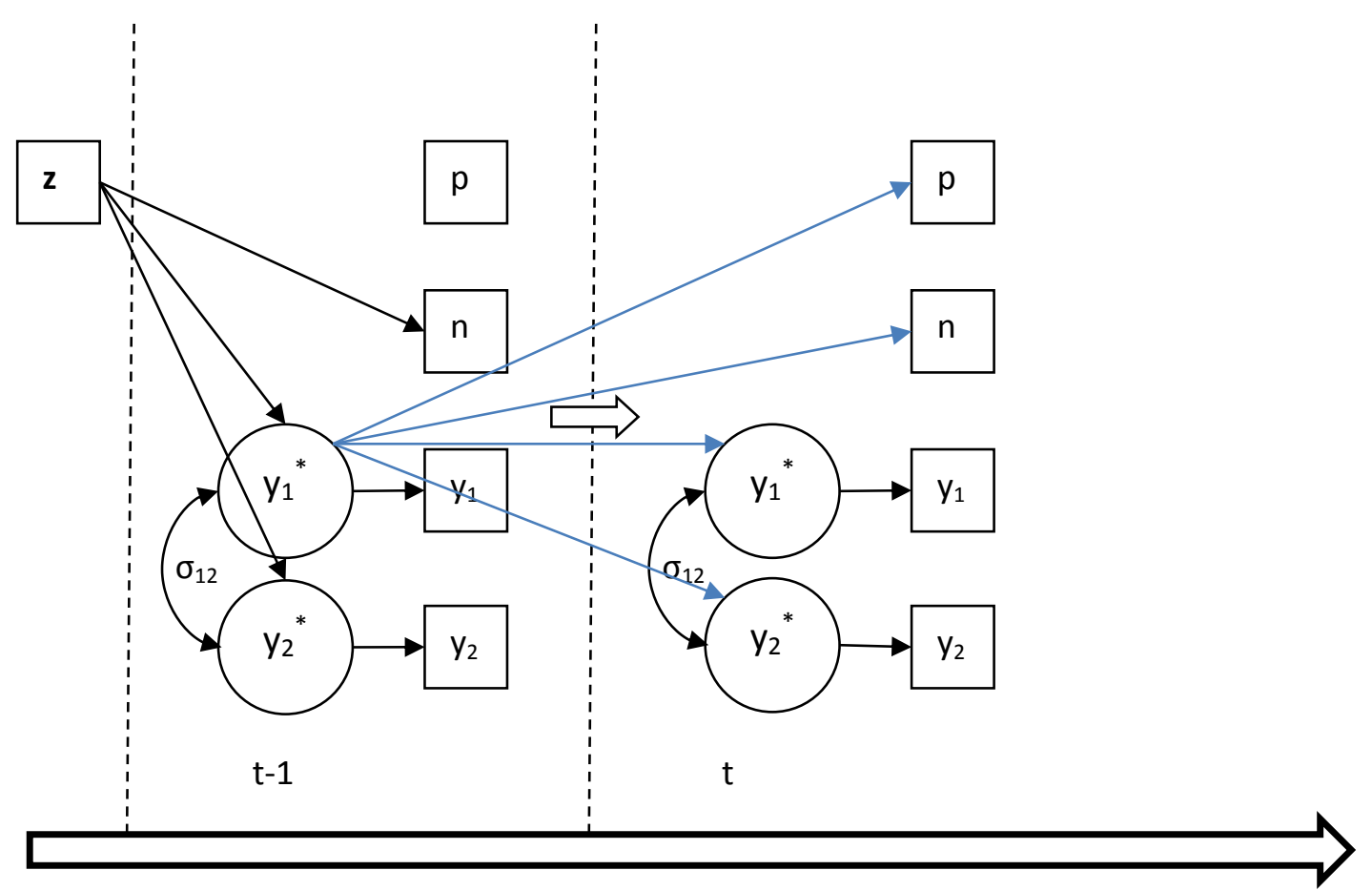

Note: To simplify the structure, the figure shows only two positions (labelled $\mathrm{y}_{1}$ and $\mathrm{y}_{2}$ ) and two continuous measures for networks (n) and firm performance (p). Subscripts for individuals (i) and time (t) are omitted. Certain characteristics of agents were determined at birth or long before they took their first position. These variables are captured in vector $\mathbf{z}$. The model recognizes the underlying latent variables $\mathrm{y}_{1}{ }^{*}$ and $\mathrm{y}_{2}{ }^{*}$ that lead to positions. These latent variables can be correlated (indicated by the covariance $\sigma_{12}$ and the curved arrow). Latent variables $\left(\mathrm{y}_{1}{ }^{*}, \mathrm{y}_{2}{ }^{*}\right)$ and continuous variables $(\mathrm{p}, \mathrm{n})$ at $\mathrm{t}-1$ explain latent variables $\left(\mathrm{y}_{1}{ }^{*}\right.$, $\left.\mathrm{y}_{2}{ }^{*}\right)$ and continuous variables $(\mathrm{p}, \mathrm{n})$ at $\mathrm{t}$, resembling a $\operatorname{VAR}(1)$ in reduced form. We indicate these impacts for the latent variable $\mathrm{y}_{1}{ }^{*}$ at $\mathrm{t}-1$, which affects its own value, the second latent variable $\mathrm{y}_{2}{ }^{*}$ and the two continuous variables at $\mathrm{t}$. To avoid confusion, the figure does not show all the arrows from $\mathrm{t}-1$ to $\mathrm{t}$, as all four dependent variables at $\mathrm{t}-1$ affect all four dependent variables at $\mathrm{t}$ implying 16 arrows. 


\section{Figure 2: Trace plots and PSFR}

Panel A shows the trace plot of parameter $b[3]$ that measures the partial impact of the latent variable $\mathrm{y}_{2}{ }^{*}$ that determines whether the agent was a corporate networker in 1998 on the probability of being a CEO in 2004. Both chains converge to the target distribution after about 1500 iterations.

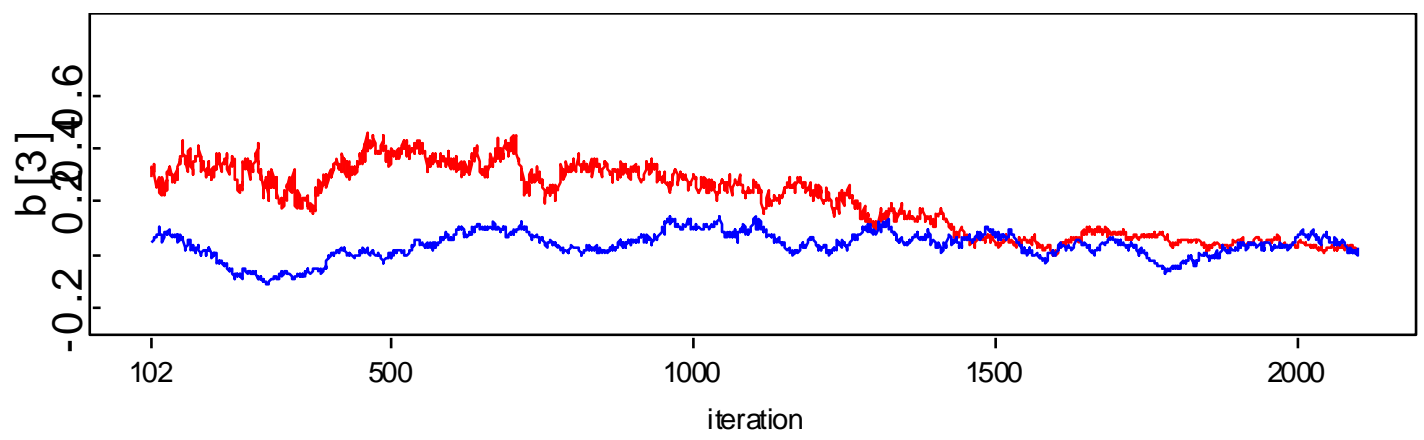

Panel B shows the PSFR for b[3]. It plots the PSFR in red, the pooled variance in green and the average variance in blue.

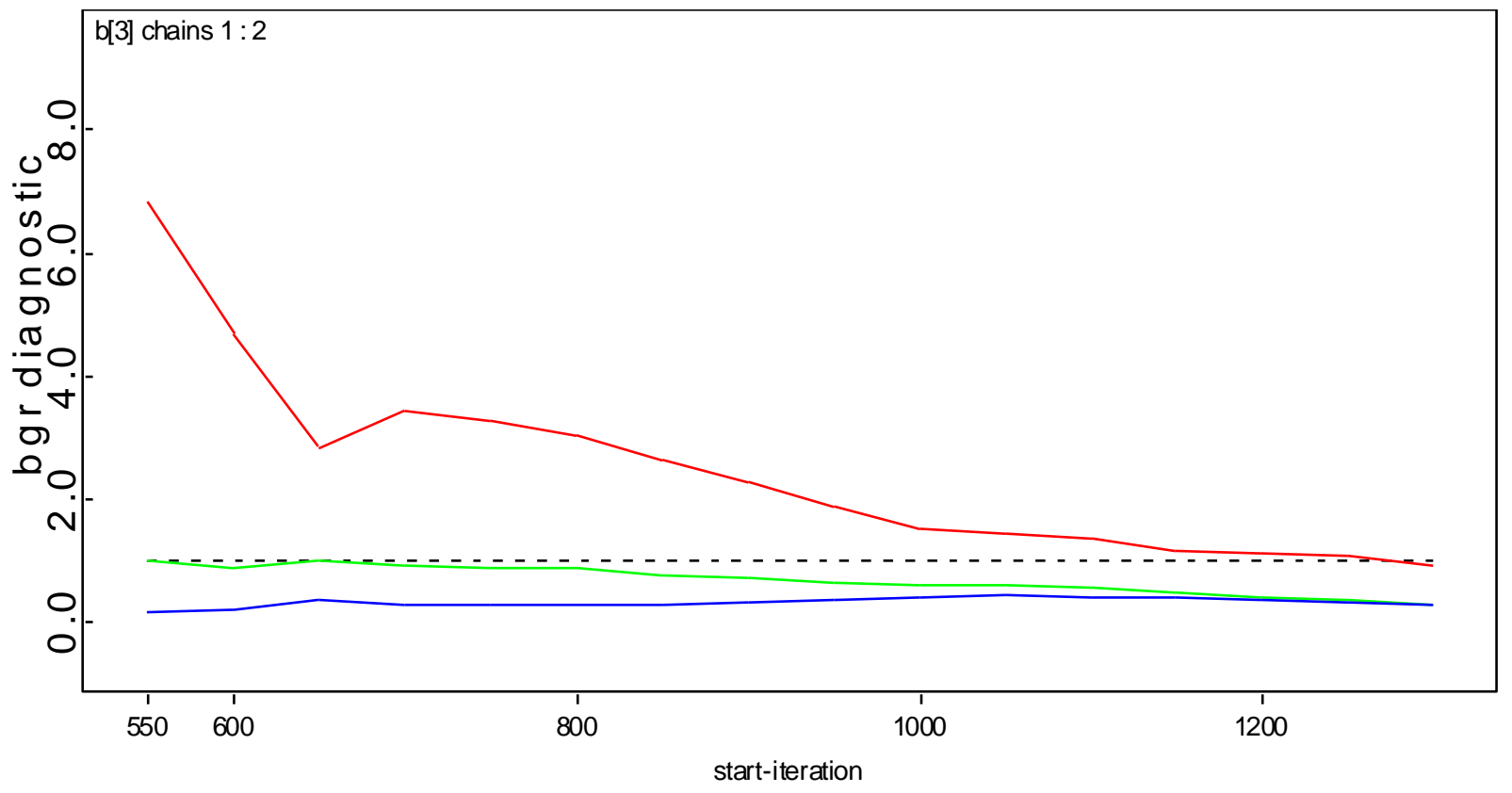


Table 1: Change in positions 1998-2004

\begin{tabular}{lllll}
\hline \multicolumn{5}{l}{ Panel A: Comparing initial and final positions } \\
\hline & Y1 & Y2 & Y3 & Y4 \\
\hline Initial position in 1998 & 484 & 388 & 473 & 52 \\
Leaving & 184 & 197 & 173 & 0 \\
Natural cause & 0 & 51 & 50 & 12 \\
Joining & 6 & 40 & 54 & 0 \\
\hline Position in 2004 & 294 & 181 & 246 & 40 \\
\hline
\end{tabular}

\begin{tabular}{llllll}
\hline \multicolumn{2}{l}{ Panel B: Movements between positions } & (a) & & & \\
\hline Initial positions & Y1 & Y2 & Y3 & Y4 & None \\
\hline Y1 & 294 & 36 & 68 & 4 & 76 \\
Y2 & 47 & 181 & 160 & 16 & 28 \\
Y3 & 40 & 95 & 173 & 12 & 40 \\
Y4 & 0 & 0 & 0 & 40 & 0 \\
\hline
\end{tabular}

(a) Panel B only considers agents that did not exit due to natural causes. Agents can hold several positions. 
Table 2: Model I: Positions

\begin{tabular}{|c|c|c|c|c|c|c|c|c|c|c|c|c|c|c|}
\hline \multirow[b]{3}{*}{ Covariates } & \multicolumn{14}{|c|}{ Dependent variables } \\
\hline & \multicolumn{2}{|c|}{$\mathrm{y}_{1}^{*}(\mathrm{t})$} & \multicolumn{2}{|l|}{$\mathrm{y}_{2}^{*}(\mathrm{t})$} & \multicolumn{2}{|l|}{$\mathrm{y}_{3}^{*}(\mathrm{t})$} & \multicolumn{2}{|c|}{$\mathrm{y}_{1}{ }^{*}(\mathrm{t}-1)$} & \multicolumn{2}{|c|}{$\mathrm{y}_{2}{ }^{*}(\mathrm{t}-1)$} & \multicolumn{2}{|l|}{$\mathrm{y}_{3}{ }^{*}(\mathrm{t}-1)$} & \multicolumn{2}{|c|}{$\mathrm{y}_{4}^{*}(\mathrm{t}-1)$} \\
\hline & $2.5 \%$ & $97.5 \%$ & $2.5 \%$ & $97.5 \%$ & $2.5 \%$ & $97.5 \%$ & $2.5 \%$ & $97.5 \%$ & $2.5 \%$ & $97.5 \%$ & $2.5 \%$ & $97.5 \%$ & $2.5 \%$ & $97.5 \%$ \\
\hline $\mathrm{y}_{1}^{*}(\mathrm{t}-1)$ & 0.22 & 0.59 & -0.20 & -0.03 & -0.14 & 0.11 & - & - & - & - & - & - & - & - \\
\hline $\mathrm{y}_{2}^{*}(\mathrm{t}-1)$ & 0.19 & 0.57 & 0.73 & 1.17 & 0.23 & 0.60 & - & - & - & - & - & - & - & - \\
\hline $\mathrm{y}_{3}^{*}(\mathrm{t}-1)$ & -0.10 & 0.20 & -0.09 & 0.10 & -0.14 & 0.11 & - & - & - & - & - & - & - & - \\
\hline $\mathrm{y}_{4}{ }^{*}(\mathrm{t}-1)$ & 0.00 & 0.75 & -0.02 & 0.35 & -0.06 & 0.46 & - & - & - & - & - & - & - & - \\
\hline class_2 & - & - & - & - & - & - & -0.05 & 0.01 & -0.01 & 0.05 & -0.01 & 0.09 & -0.02 & 0.03 \\
\hline class_3 & - & - & - & - & - & - & -0.03 & 0.03 & -0.03 & 0.02 & -0.03 & 0.06 & -0.01 & 0.04 \\
\hline gender & - & - & - & - & - & - & 0.00 & 0.06 & -0.03 & 0.04 & -0.05 & 0.03 & -0.01 & 0.03 \\
\hline nation & - & - & - & - & - & - & 0.02 & 0.07 & -0.10 & -0.04 & -0.06 & 0.00 & -0.02 & 0.01 \\
\hline age & - & - & - & - & - & - & -0.06 & -0.03 & -0.01 & 0.01 & -0.06 & -0.02 & 0.01 & 0.02 \\
\hline $\mathrm{ES}$ & - & - & - & - & - & - & -0.02 & 0.00 & -0.01 & 0.02 & 0.00 & 0.03 & -0.01 & 0.01 \\
\hline & \multicolumn{14}{|c|}{ Details on MCMC } \\
\hline Observations & 391 & & & & & & & & & & & & & \\
\hline Burn-in & 1000 & & & & & & & & & & & & & \\
\hline Iterations & 6000 & & & & & & & & & & & & & \\
\hline
\end{tabular}

Note: The table reports the 2.5 and 97.5 percentile of posterior distributions of parameters. A set of exogenous variables including social class, gender, nationality, age and attending elite school and universities are covariates for initial positions at $t-1$. Initial positions at t- 1 affect current positions at $\mathrm{t}$ through their latent variables constituting a multivariate probit with VAR(1) structure. Correlation between latent variables is permitted. 
Table 3: Model II: Positions and networks

Panel A: Size of corporate networks due to interlocks (SIZE)

\begin{tabular}{|c|c|c|c|c|c|c|c|c|c|c|}
\hline Covariates & $\mathrm{y} 1 *(\mathrm{t})$ & $\mathrm{y} 2 *(\mathrm{t})$ & $\mathrm{y} 3 *(\mathrm{t})$ & SIZE (t) & Covariates & $\mathrm{y}_{1}{ }^{*}(\mathrm{t}-1)$ & $\mathrm{y}_{2}{ }^{*}(\mathrm{t}-1)$ & $\mathrm{y}_{3}{ }^{*}(\mathrm{t}-1)$ & $\mathrm{y}_{4}{ }^{*}(\mathrm{t}-1)$ & $\operatorname{SIZE}(\mathrm{t}-1)$ \\
\hline $\mathrm{y}_{1}{ }^{*}(\mathrm{t}-1)$ & $0.20 *$ & -0.07 & 0.27 & 0.04 & class_1 & -0.07 & $0.10^{*}$ & $0.14 *$ & $0.03 *$ & 0.03 \\
\hline $\mathrm{y}_{2}{ }^{*}(\mathrm{t}-1)$ & $0.23 *$ & $0.64 *$ & $0.91 *$ & -0.01 & class_2 & -0.05 & $0.07 *$ & $0.11 *$ & 0.02 & 0.02 \\
\hline $\mathrm{y}_{3}{ }^{*}(\mathrm{t}-1)$ & 0.04 & -0.06 & 0.35 & -0.01 & class_3 & -0.01 & -0.02 & 0.06 & 0.02 & -0.02 \\
\hline $\mathrm{y}_{4}^{*}(\mathrm{t}-1)$ & $0.57 *$ & -0.08 & -0.18 & 0.34 & gender & 0.03 & 0.03 & 0.00 & 0.01 & 0.01 \\
\hline \multirow[t]{4}{*}{$\operatorname{SIZE}(\mathrm{t}-1)$} & -0.08 & 0.02 & $-1.07 *$ & -0.08 & nation & 0.08* & $-0.18 *$ & -0.01 & -0.01 & $-0.09 *$ \\
\hline & & & & & age & $-0.10 *$ & 0.02 & $-0.07 *$ & $0.01 *$ & $-0.05 *$ \\
\hline & & & & & ES & -0.02 & 0.03* & 0.02 & 0.01* & 0.01 \\
\hline & & & & & $\mathrm{EH}$ & 0.01 & $0.05 *$ & 0.00 & 0.00 & 0.02 \\
\hline
\end{tabular}

\begin{tabular}{|c|c|c|c|c|c|c|c|c|c|c|}
\hline \multicolumn{11}{|c|}{ Panel B: Number of corporate and extra-corporate networks (NUM) } \\
\hline Covariates & $\mathrm{y} 1 *(\mathrm{t})$ & $\mathrm{y} 2 *(\mathrm{t})$ & $\mathrm{y} 3 *(\mathrm{t})$ & NUM(t) & Covariates & $\mathrm{y}_{1}^{*}(\mathrm{t}-1)$ & $\mathrm{y}_{2}{ }^{*}(\mathrm{t}-1)$ & $\mathrm{y}_{3}{ }^{*}(\mathrm{t}-1)$ & $\mathrm{y}_{4}{ }^{*}(\mathrm{t}-1)$ & $\operatorname{NUM}(\mathrm{t}-1)$ \\
\hline $\mathrm{y}_{2}^{*}(\mathrm{t}-1)$ & $0.16 *$ & $0.55 *$ & $0.45 *$ & -0.02 & class_2 & -0.04 & $0.09 *$ & $0.09 *$ & 0.01 & $0.06 *$ \\
\hline $\mathrm{y}_{4}^{*}(\mathrm{t}-1)$ & $0.25 *$ & 0.00 & 0.32 & $0.22 *$ & gender & 0.04 & 0.03 & 0.00 & $0.03 *$ & -0.06 \\
\hline \multirow[t]{2}{*}{$\operatorname{NUM}(t-1)$} & -0.15 & 0.19 & -0.47 & $-0.28 *$ & nation & 0.07 & $-0.15^{*}$ & -0.05 & -0.01 & -0.03 \\
\hline & & & & & age & $-0.11 *$ & 0.01 & $-0.08 *$ & $0.02 *$ & -0.05 \\
\hline
\end{tabular}




\begin{tabular}{|c|c|c|c|c|c|c|c|c|c|c|}
\hline \multicolumn{11}{|c|}{ Panel C: Number of life worlds spanned through networks (SPAN) } \\
\hline Covariates & $\mathrm{y} 1 *(\mathrm{t})$ & $\mathrm{y} 2 *(\mathrm{t})$ & $\mathrm{y} 3 *(\mathrm{t})$ & $\operatorname{SPAN}(\mathrm{t})$ & Covariates & $\mathrm{y}_{1}{ }^{*}(\mathrm{t}-1)$ & $\mathrm{y}_{2}^{*}(\mathrm{t}-1)$ & $\mathrm{y}_{3}^{*}(\mathrm{t}-1)$ & $\mathrm{y}_{4}^{*}(\mathrm{t}-1)$ & SPAN(t-1) \\
\hline $\mathrm{y}_{2}{ }^{*}(\mathrm{t}-1)$ & $0.33 *$ & $0.81 *$ & $0.96 *$ & 0.10 & class_2 & -0.05 & 0.02 & $0.04 *$ & -0.01 & $0.04 *$ \\
\hline $\mathrm{y}_{4}^{*}(\mathrm{t}-1)$ & 0.35 & $0.35 *$ & -0.72 & -0.10 & gender & 0.04 & 0.02 & -0.01 & $0.02 *$ & -0.03 \\
\hline \multirow[t]{2}{*}{$\operatorname{SPAN}(\mathrm{t}-1)$} & -0.35 & 0.05 & -1.23 & -0.31 & nation & 0.10* & $-0.12 *$ & -0.02 & 0.00 & -0.04 \\
\hline & & & & & age & $-0.09 *$ & 0.01 & $-0.06 *$ & $0.01 *$ & $-0.05^{*}$ \\
\hline
\end{tabular}

Note: The table reports medians of estimated parameters. A star $(*)$ indicates whether the $95 \%$ credibility interval contains zero; hence, it indicates statistical significance (i.e. whether the parameter is significantly different from zero). Each panel uses a different measure of networks. 
Table 4: Standard probit models assuming networks are exogenous

\begin{tabular}{lllllll}
\hline Covariates & $\mathrm{y}_{1}(\mathrm{t})$ & $\mathrm{y}_{1}(\mathrm{t})$ & $\mathrm{y}_{1}(\mathrm{t})$ & $\mathrm{y}_{1}(\mathrm{t})$ & $\mathrm{y}_{1}(\mathrm{t})$ & $\mathrm{y}_{1}(\mathrm{t})$ \\
\hline $\mathrm{y}_{1}(\mathrm{t}-1)$ & - & $1.17^{* * *}$ & - & $1.18^{* * *}$ & - & $1.14^{* * *}$ \\
$\mathrm{y}_{2}(\mathrm{t}-1)$ & - & $0.88^{* * *}$ & - & 0.27 & - & 0.29 \\
$\mathrm{y}_{3}(\mathrm{t}-1)$ & - & $0.67 * *$ & - & $0.63^{* *}$ & - & 0.27 \\
$\mathrm{y}_{4}(\mathrm{t}-1)$ & - & $1.33^{* *}$ & - & $1.35^{* *}$ & - & $1.25^{* *}$ \\
$\mathrm{SIZE}(\mathrm{t}-1)$ & $0.59 * * *$ & -0.36 & - & - & - & - \\
$\mathrm{NUM}(\mathrm{t}-1)$ & - & - & $0.90^{* * *}$ & $0.77 * *$ & - & - \\
SPAN $(\mathrm{t}-1)$ & - & - & - & - & $1.90^{* * *}$ & $1.71^{* * *}$ \\
\hline Pseudo $\mathrm{R}^{2}$ & 0.04 & 0.28 & 0.10 & 0.30 & 0.25 & 0.38 \\
\hline
\end{tabular}

Note: $* \mathrm{p}<0.05 ; * * \mathrm{p}<0.01 ; * * * \mathrm{p}<0.001$. We run standard probit models explain being a $\mathrm{CEO}$ at point in time $\mathrm{t}$ using the three measures of networks, the size of corporate networks (SIZE), the size of corporate and extra-corporate networks $(N U M)$ and the number of lifeworlds spanned $(S P A N)$. We first run models with the network variable on its own and then re-run models including agents' past positions. The table reports the coefficient, the pseudo R-squared and indicates significance. 
Table 5: Model III: Positions, networks and performance

\begin{tabular}{|c|c|c|c|c|c|c|c|c|c|c|c|}
\hline \multicolumn{12}{|c|}{ Panel A: Size of corporate networks due to interlocks (SIZE) } \\
\hline Covariates & $\mathrm{y} 1 *(\mathrm{t})$ & $\mathrm{y} 2 *(\mathrm{t})$ & $\mathrm{y} 3 *(\mathrm{t})$ & $\operatorname{SIZE}(\mathrm{t})$ & $\mathrm{ROA}(\mathrm{t})$ & Covariates & $\mathrm{y}_{1}^{*}(\mathrm{t}-1)$ & $\mathrm{y}_{2}^{*}(\mathrm{t}-1)$ & $\mathrm{y}_{3}{ }^{*}(\mathrm{t}-1)$ & $\mathrm{y}_{4}^{*}(\mathrm{t}-1)$ & $\operatorname{SIZE}(\mathrm{t}-1)$ \\
\hline $\mathrm{y}_{1}^{*}(\mathrm{t}-1)$ & $0.96 *$ & -0.59 & -0.70 & 0.41 & 0.18 & class_1 & -0.03 & $0.04 *$ & $\mathbf{0 . 0 5 *}$ & 0.01 & 0.01 \\
\hline $\mathrm{y}_{2}{ }^{*}(\mathrm{t}-1)$ & $1.18 *$ & $5.39 *$ & $3.05 *$ & -1.06 & -0.87 & class_2 & -0.02 & $0.03 *$ & $0.04 *$ & 0.00 & 0.00 \\
\hline $\mathrm{y}_{3}{ }^{*}(\mathrm{t}-1)$ & 0.75 & 0.59 & 0.13 & 0.74 & 0.63 & class_3 & -0.01 & 0.01 & $0.03^{*}$ & 0.01 & 0.01 \\
\hline $\mathrm{y}_{4}^{*}(\mathrm{t}-1)$ & $1.39 *$ & -0.65 & 0.31 & 1.28 & 0.91 & gender & 0.01 & 0.02 & 0.00 & 0.00 & $0.01 *$ \\
\hline $\operatorname{SIZE}(\mathrm{t}-1)$ & -0.46 & -0.39 & 0.18 & 0.88 & 2.39 & nation & $0.03 *$ & $-0.05 *$ & 0.00 & 0.01 & $0.02 *$ \\
\hline \multirow[t]{3}{*}{$\operatorname{ROA}(\mathrm{t}-1)$} & 0.33 & $2.17 *$ & $2.60 *$ & 1.07 & 1.43 & age & -0.03 & 0.00 & $-0.02 *$ & $0.01 *$ & -0.01 \\
\hline & & & & & & ES & -0.01 & 0.01 & -0.01 & $0.00 *$ & -0.01 \\
\hline & & & & & & $\mathrm{EH}$ & 0.00 & 0.00 & 0.00 & 0.00 & 0.00 \\
\hline \multicolumn{12}{|c|}{ Panel B: Number of corporate and extra-corporate networks (NUM) } \\
\hline Covariates & $\mathrm{y} 1 *(\mathrm{t})$ & $\mathrm{y} 2 *(\mathrm{t})$ & $\mathrm{y} 3 *(\mathrm{t})$ & NUM(t) & $\mathrm{ROA}(\mathrm{t})$ & Covariates & $\mathrm{y}_{1}^{*}(\mathrm{t}-1)$ & $\mathrm{y}_{2}^{*}(\mathrm{t}-1)$ & $\mathrm{y}_{3}^{*}(\mathrm{t}-1)$ & $\mathrm{y}_{4}^{*}(\mathrm{t}-1)$ & $\operatorname{NUM}(\mathrm{t}-1)$ \\
\hline $\mathrm{y}_{1}{ }^{*}(\mathrm{t}-1)$ & $1.36 *$ & -0.59 & -0.84 & 0.04 & -0.76 & class_1 & -0.01 & $0.04 *$ & $\mathbf{0 . 0 3 *}$ & 0.03 & 0.00 \\
\hline $\mathrm{y}_{2}^{*}(\mathrm{t}-1)$ & $2.08 *$ & $4.24 *$ & $3.07 *$ & -1.38 & -0.17 & class_2 & -0.01 & $0.03 *$ & $0.03 *$ & 0.02 & -0.01 \\
\hline $\mathrm{y}_{3}{ }^{*}(\mathrm{t}-1)$ & 0.37 & $0.88 *$ & 0.37 & 0.12 & -0.02 & class_3 & 0.00 & 0.01 & 0.01 & 0.02 & -0.01 \\
\hline $\mathrm{y}_{4}{ }^{*}(\mathrm{t}-1)$ & 0.22 & 0.20 & 0.17 & $1.46^{*}$ & $1.86^{*}$ & gender & 0.01 & 0.01 & 0.01 & 0.02 & 0.01 \\
\hline NUM(t-1) & 0.26 & -0.32 & 0.56 & 0.55 & 0.55 & nation & $0.04 *$ & $-0.06 *$ & -0.02 & 0.02 & 0.02 \\
\hline \multirow[t]{3}{*}{$\mathrm{ROA}(\mathrm{t}-1)$} & 0.36 & $1.75 *$ & 1.39 & -0.57 & 0.86 & age & $-0.03 *$ & 0.00 & $-0.03 *$ & 0.01 & -0.01 \\
\hline & & & & & & ES & -0.01 & 0.01 & 0.01 & 0.00 & -0.01 \\
\hline & & & & & & EH & 0.00 & 0.01 & 0.00 & -0.01 & -0.01 \\
\hline
\end{tabular}




\begin{tabular}{|c|c|c|c|c|c|c|c|c|c|c|c|}
\hline \multicolumn{12}{|c|}{ Panel C: Number of life worlds spanned through networks (SPAN) } \\
\hline Covariates & $\mathrm{y} 1 *(\mathrm{t})$ & $\mathrm{y} 2 *(\mathrm{t})$ & $\mathrm{y} 3 *(\mathrm{t})$ & SPAN(t) & $\operatorname{ROA}(\mathrm{t})$ & Covariates & $\mathrm{y}_{1}{ }^{*}(\mathrm{t}-1)$ & $\mathrm{y}_{2}{ }^{*}(\mathrm{t}-1)$ & $\mathrm{y}_{3}{ }^{*}(\mathrm{t}-1)$ & $\mathrm{y}_{4}{ }^{*}(\mathrm{t}-1)$ & SPAN(t-1) \\
\hline $\mathrm{y}_{1}^{*}(\mathrm{t}-1)$ & $1.36 *$ & -0.59 & -0.84 & 0.04 & -0.76 & class_1 & -0.01 & $0.04 *$ & $\mathbf{0 . 0 3 *}$ & 0.03 & 0.00 \\
\hline $\mathrm{y}_{2}^{*}(\mathrm{t}-1)$ & $2.08 *$ & $4.24 *$ & $3.07 *$ & -1.38 & -0.17 & class_2 & -0.01 & 0.03* & $0.03 *$ & 0.02 & -0.01 \\
\hline $\mathrm{y}_{3}{ }^{*}(\mathrm{t}-1)$ & 0.37 & $0.88 *$ & 0.37 & 0.12 & -0.02 & class_3 & 0.00 & 0.01 & 0.01 & 0.02 & -0.01 \\
\hline $\mathrm{y}_{4}^{*}(\mathrm{t}-1)$ & 0.22 & 0.20 & 0.17 & $1.46^{*}$ & $1.86^{*}$ & gender & 0.01 & 0.01 & 0.01 & 0.02 & 0.01 \\
\hline $\operatorname{SPAN}(\mathrm{t}-1)$ & 0.26 & -0.32 & 0.56 & 0.55 & 0.55 & nation & $0.04 *$ & -0.06 & -0.02 & 0.02 & 0.02 \\
\hline \multirow[t]{3}{*}{$\operatorname{ROA}(\mathrm{t}-1)$} & 0.36 & $1.75^{*}$ & 1.39 & -0.57 & 0.86 & age & $-0.03 *$ & 0.00 & $-0.03^{*}$ & 0.01 & -0.01 \\
\hline & & & & & & ES & -0.01 & 0.01 & 0.01 & 0.00 & -0.01 \\
\hline & & & & & & $\mathrm{EH}$ & 0.00 & 0.01 & 0.00 & -0.01 & -0.01 \\
\hline
\end{tabular}

Note: The table reports medians of estimated parameters. A star $(*)$ indicates whether the $95 \%$ credibility interval contains zero; hence, it indicates statistical significance (i.e. whether the parameter is significantly different from zero). Each panel uses a different measure of networks. 
Appendix A

\begin{tabular}{|c|c|c|}
\hline Variable & Name & Type of variable \\
\hline $\mathrm{y}_{1}$ & $\begin{array}{l}\text { Top-tier executive (CEO or Executive } \\
\text { Chairman) }\end{array}$ & Dummy variable \\
\hline $\mathrm{y}_{2}$ & $\begin{array}{l}\text { Corporate networkers having at least } \\
\text { two directorships of top } 100 \text { companies } \\
\text { or one plus at least two other company } \\
\text { directorships. }\end{array}$ & Dummy variable \\
\hline $\mathrm{y}_{3}$ & $\begin{array}{l}\text { Membership of two or more extra- } \\
\text { corporate boards }\end{array}$ & Dummy variable \\
\hline $\mathrm{y}_{4}$ & $\begin{array}{l}\text { Company founder retaining } 25 \% \text { or } \\
\text { more of equity }\end{array}$ & Dummy variable \\
\hline ES & Elite school & Dummy variable \\
\hline $\mathrm{EH}$ & Elite higher education & Dummy variable \\
\hline $\begin{array}{l}\text { class_1 to } \\
\text { class_3 }\end{array}$ & Social class & $\begin{array}{l}\text { Four categories and thus } \\
\text { three dummy variables }\end{array}$ \\
\hline gender & Gender & $\begin{array}{l}\text { Dummy variable: } 1 \text { for } \\
\text { males and } 0 \text { for females }\end{array}$ \\
\hline age98 & Age & Continuous variable in years \\
\hline nation & Nationality & $\begin{array}{l}\text { Dummy variable: } 1 \text { for } \\
\text { French nationals and } 0 \text { for } \\
\text { others }\end{array}$ \\
\hline NUM & $\begin{array}{l}\text { Total number of corporate and extra- } \\
\text { corporate board memberships }\end{array}$ & Continuous variable \\
\hline SPAN & $\begin{array}{l}\text { Number of life-worlds involved in at } \\
\text { highest level from executive director, } \\
\text { non-executive director, public or } \\
\text { political body, business association, } \\
\text { charitable foundation, education or } \\
\text { research, arts or sports }\end{array}$ & Continuous variable \\
\hline SIZE & $\begin{array}{l}\text { Size of interfirm network defined by } \\
\text { the number of interlocks }\end{array}$ & Continuous variable \\
\hline ROA & Return on assets & Continuous variable \\
\hline
\end{tabular}




\section{Appendix B}

We provide our OpenBUGS code for the QSP-VAR (MODEL II). Please note that the data structure depends on your sample, and there are many ways of coding your data in OpenBUGS (see user manual for more details). We provide comments for every step.

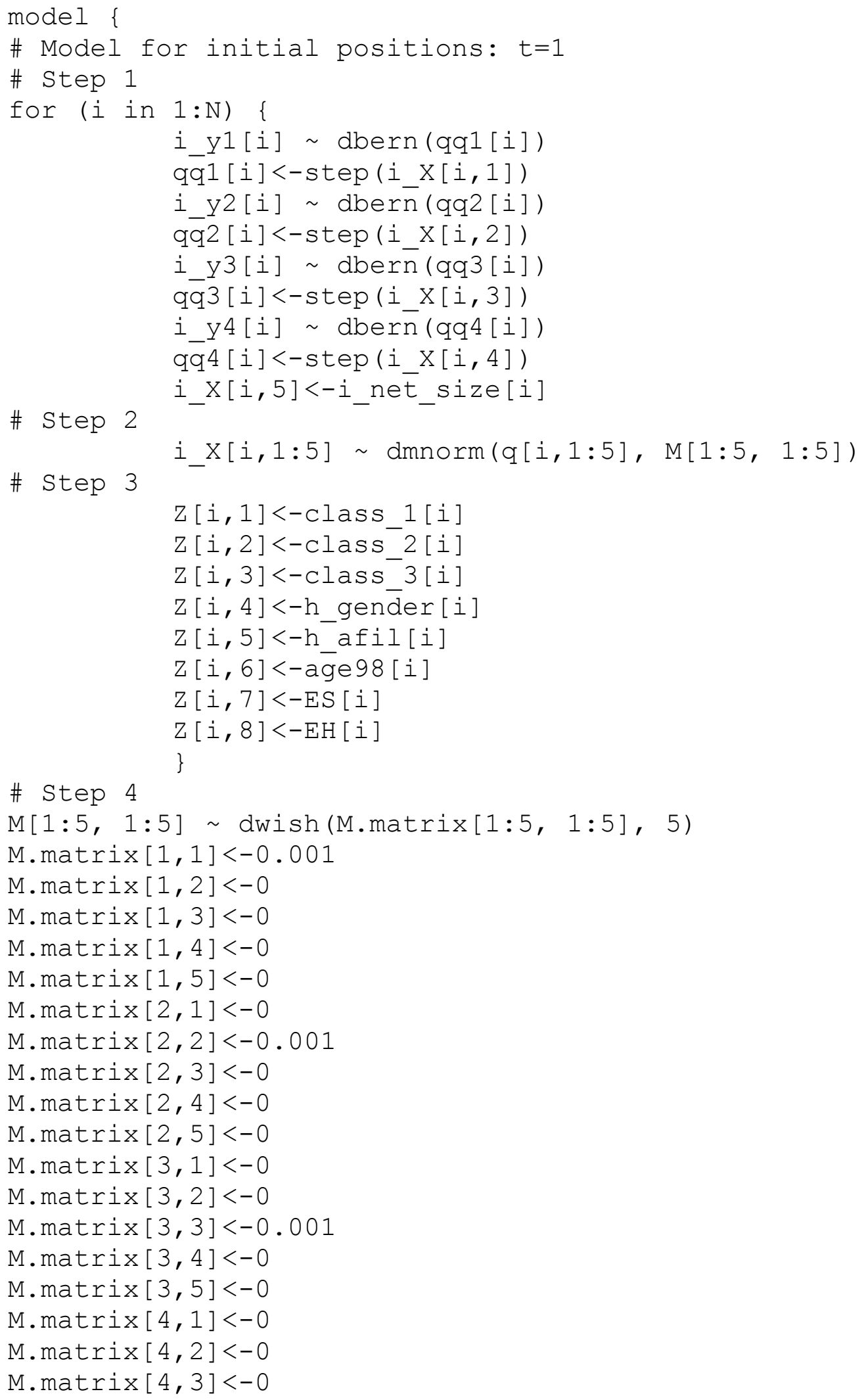




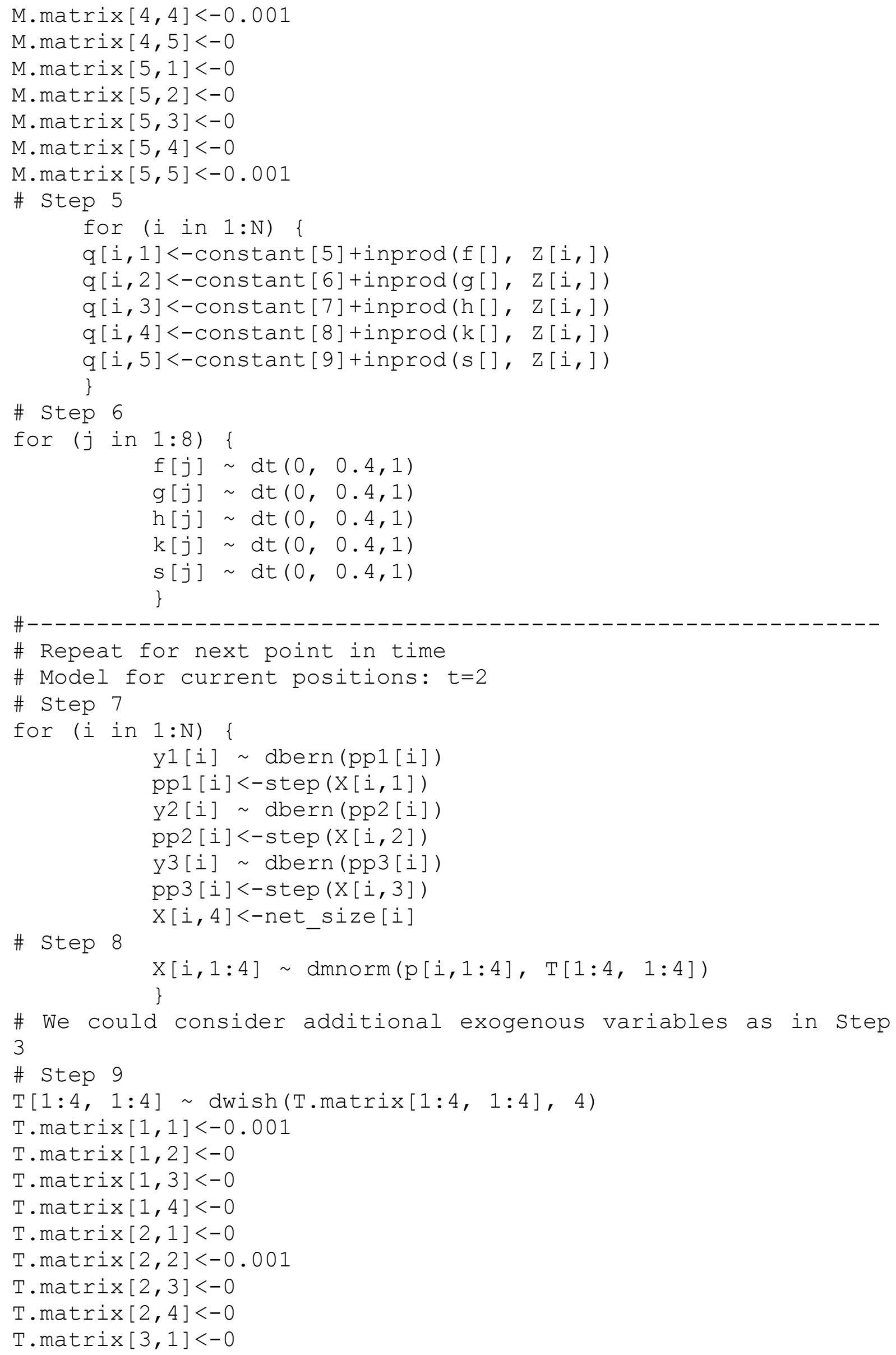




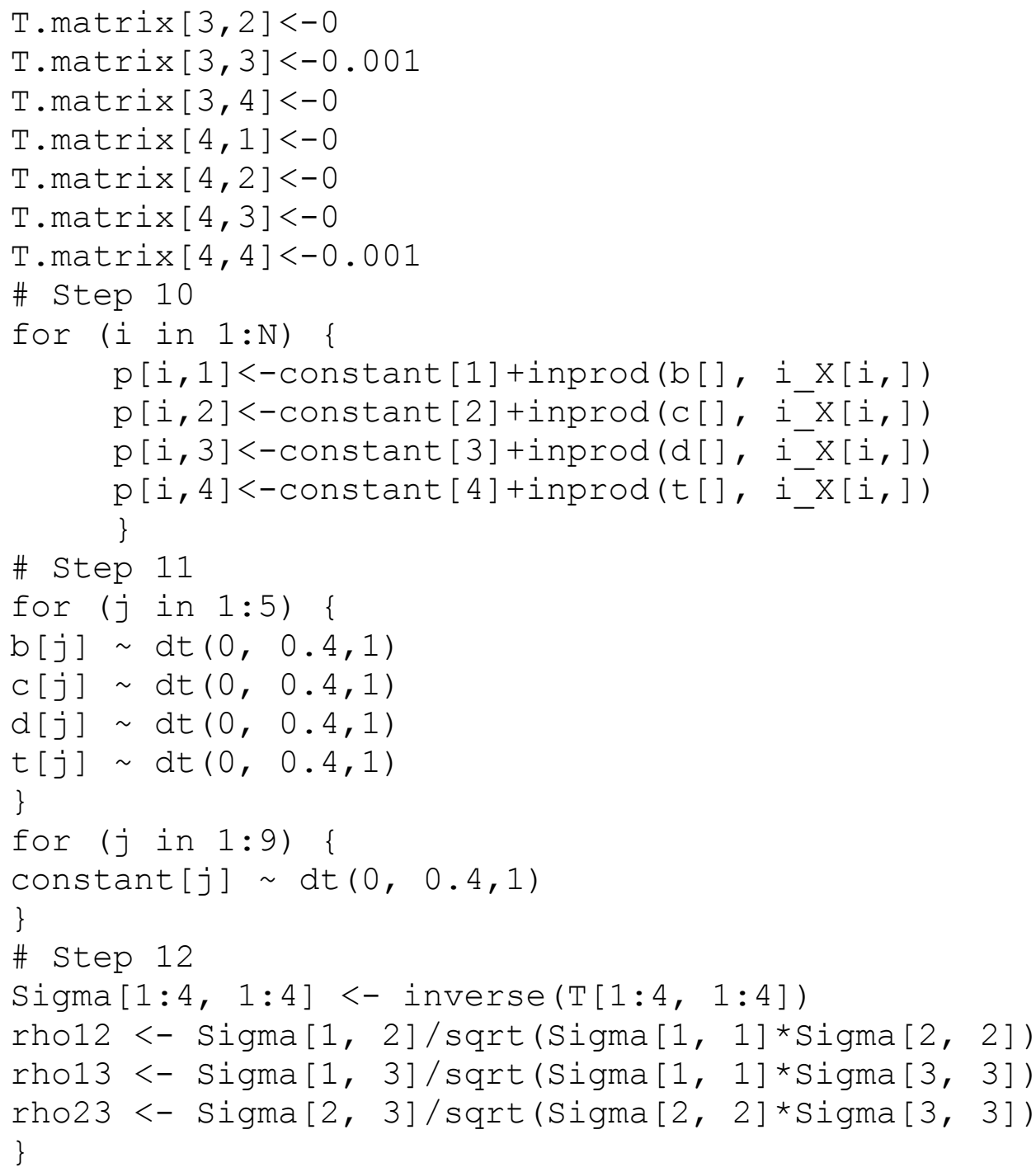

\section{Comments}

\# Step 1 defines the multivariate probit element of the QSP-VAR linking observed positions to latent variables through a degenerate Bernoulli distribution (Lunn et al., 2006).

\# Step 2 sets the multivariate normal as a prior for the vector of latent variables (Lunn et al., 2009). It is important to note that we also include the initial size of networks into the initial vector $\left(i \_x[i, 5]<-i\right.$ net_size $\left.[i]\right)$. Hence, the initial vector contains a mix of latent variables, which are linked to binary outcomes, and a continuous variable.

\# Step 3 defines the vector $\mathbf{z}$ for exogenous variables. Based on our model, these exogenous variables only affect initial positions. Of course, this can be modified by including the vector $\mathbf{z}$ into the model for current positions.

\# Step 4 defines the prior for the precision matrix using an inverted Wishart distribution (Lunn et al., 2009). 
\# Step 5 specifies the mean equations for the initial positions. Initial positions depend on a set of exogenous variables, the 'variables of fate', which also affect network size in the fifth equation.

\# Step 6 applies weakly informative priors for parameters of the probit model based on Gelman et al. (2008).

\# Accordingly, Steps 1 to 6 explain how individuals obtained their initial positions (e.g. due to their education). Researchers might omit modelling starting points, depending on their access to exogenous variables.

\# Step 7 is similar to Step 1.

\# Step 8 is similar to Step 2.

\# Step 9 is similar to Step 4.

\# Step 10 represents the core element of the QSP-VAR as it specifies the mean equations for the current positions at $t=2$, which depend on initial positions at $t=1$ and the initial size of networks. Hence, Step 10 captures the autoregressive nature of the model.

\# Step 11 is similar to Step 6.

\# Step 12 explores correlations between current positions. As suggested in MODEL I, correlations should be considered before using a multivariate probit approach. If there is no evidence for correlation between latent variables, a univariate approach could be adopted reducing computation time.

\section{Different data formats for panel data}

OpenBUGS allows several methods to store panel data. Depending on the data format, the code needs to be adjusted.

EXAMPLE: The position of three individuals measured at three points in time $t=1,2,3$.

$\begin{array}{llll} & \mathrm{t}=1 & \mathrm{t}=2 & \mathrm{t}=3 \\ \text { Individual 1 } & 1 & 0 & 0 \\ \text { Individual 2 } & 0 & 1 & 1 \\ \text { Individual 3 } & 0 & 0 & 1\end{array}$

Method I: One can use a two-dimensional array y[i,t] and store data as follows.

$\begin{array}{lll}\mathrm{y}[, 1] & \mathrm{y}[, 2] & \mathrm{y}[, 3] \\ 1 & 0 & 0 \\ 0 & 1 & 1 \\ 0 & 0 & 1\end{array}$

Method II: We rename variables for different points in time using the prefix i_for $t=2$ and ii for $\mathrm{t}=1$. Hence, we store data as follows.

$\begin{array}{lll}\text { ii_y[] } & \text { i_y[] } & \text { y[] } \\ 1 & 0 & 0 \\ 0 & 1 & 1 \\ 0 & 0 & 1\end{array}$


In addition, there are alternative methods using nested indexing, where the cross-sectional and time dimension are combined using indices indicating individuals and time. In our code, we follow Method II and use a second dimension to combine variables (e.g. the four positions). Alternatively, Method I can be used, which when combining variables would lead to multidimensional arrays. If researchers stored their data using Method I, they can simply define identities such as $y[i, 2]<-i \_y[i]$ inside a loop for all $\mathrm{i}=1,2, \ldots, \mathrm{N}$ and then use our code. Alternatively, they could modify our code using an additional loop for the time dimension.

\section{Extension for more than two points in time}

We can modify Step 10 in our code to permit additional points in time. We just focus on one position (e.g. being a CEO) to simply the notation and extend the time dimension to three points $\mathrm{t}=1,2,3$.

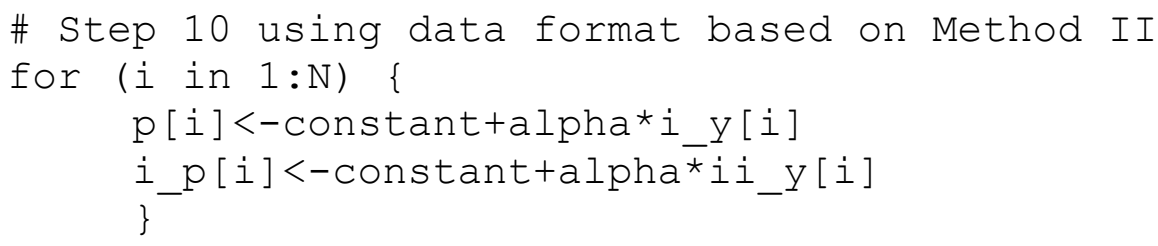

So we need to state two equations for different time periods explicitly. Note that the parameters are constant over time, i.e. constant and alpha do not change.

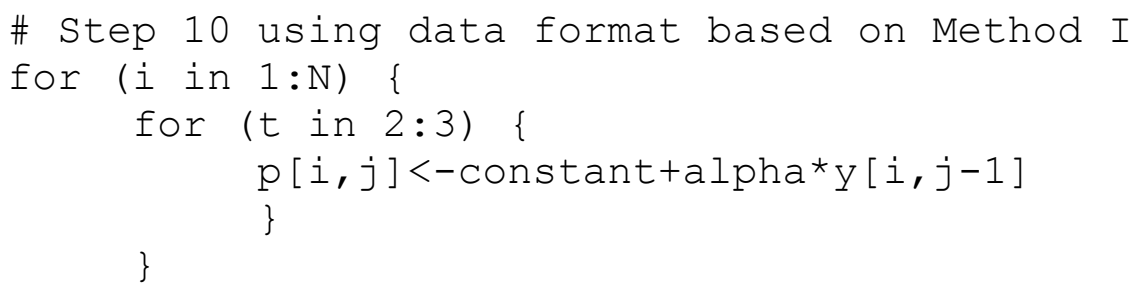

Method I requires a double loop starting at $t=2$ and ending at $t=3$, which links $y[i, 2]$ and $y[i, 1]$ as well as $y[i, 3]$ and $y[i, 2]$. Note that $t=1$ (and equivalently $i i_{-} y[i]$ ) refer to the initial position. We also need to specify what happens in the initial period, where $i \mathrm{i} p[i]($ or $p[i, 1])$ is determined. For instance, we could state that $i \mathrm{i} p \mathrm{p}[\mathrm{i}]$ (or $p[\bar{i}, 1]$ ) is driven by exogenous factors (see Steps 1 to 6 in our code). 